\title{
European evidence based consensus on the diagnosis and management of Crohn's disease: special situations
}

\author{
R Caprilli, M A Gassull, J C Escher, G Moser, P Munkholm, A Forbes, D W Hommes, H Lochs, \\ E Angelucci, A Cocco, B Vucelic, H Hildebrand, S Kolacek, L Riis, M Lukas, R de Franchis, \\ M Hamilton, G Jantschek, P Michetti, C O'Morain, M M Anwar, J L Freitas, I A Mouzas, F Baert, \\ R Mitchell, C J Hawkey, for the European Crohn's and Colitis Organisation (ECCO)
}

Gut 2006;55(Suppl I):i36-i58. doi: 10.1136/gut.2005.081950c

This third section of the European Crohn's and Colitis Organisation (ECCO) Consensus on the management of Crohn's disease concerns postoperative recurrence, fistulating disease, paediatrics, pregnancy, psychosomatics, extraintestinal manifestations, and alternative therapy. The first section on definitions and diagnosis reports on the aims and methods of the consensus, as well as sections on diagnosis, pathology, and classification of Crohn's disease. The second section on current management addresses treatment of active disease, maintenance of medically induced remission, and surgery of Crohn's disease.

See end of article for authors' affiliations

Correspondence to: Dr S P L Travis, John Radcliffe Hospital, Oxford OX3 9DU, UK; simon. travis@orh.nhs.uk;

Professor E F Stange MD $\mathrm{PhD}$, Professor of Medicine, Department of Internal Medicine 1, Robert Bosch Krankenhaus, PO Box 501120 , Auerbachstr 110,70341 Stuttgart, Germany; Eduard. Stange@rbk.de

Received

12 September 2005

Revised 18December 2005

Accepted

21 December 2005 scopic, radiological, or surgical. It is lowest when the repeat resection rate is considered, intermediate when clinical indices are used, and highest when endoscopy is used as a diagnostic tool. ${ }^{1-10}$

Data from endoscopic follow up of patients after resection of ileocaecal disease have shown that in the absence of treatment, the POR rate is around $65 \%-90 \%$ within 12 months and $80 \%-$ $100 \%$ within three years of the operation. The clinical recurrence without therapy is about $20 \%-$ $25 \%$ per year. ${ }^{10}$ It has been shown that the postoperative clinical course of $\mathrm{CD}$ is best predicted by the severity of endoscopic lesions. Symptoms, in fact, appear only when severe lesions are present, but it is not uncommon to see patients with fairly advanced recurrent lesions at endoscopy who remain asymptomatic. ${ }^{1}$ For these reasons, the sensitivity of the CDAI is poor at discriminating between patients with or
These data strongly show the need for strategies aimed at interrupting or delaying the natural course of POR. Several medications have been tried in an attempt to prevent POR, mostly with disappointing results. The aim of this consensus was therefore critically to evaluate the optimal strategies for the management of postoperative recurrence in CD. In common with other sections in the consensus, the working party (Chair: Renzo Caprilli) agreed a list of questions on POR that was circulated to ECCO members to quantify opinion on management. A systematic literature search was performed and evidence graded according to the Oxford centre for Evidence-based medicine.

\subsection{Predicting postoperative recurrence}

\section{ECCO Statement 8A}

Of the risk factors evaluated, four are considered predictors of early postoperative recurrence: absence of prophylactic treatment [ELla, RG A], smoking, disease location, and extent [EL2b, RG B]

\section{ECCO Statement 8B}

Perforating behaviour has been considered a risk factor; nevertheless the data from the literature do not support this [EL2b, RG D] without postoperative recurrence. ${ }^{11}$
Several studies have looked for potential risk factors for recurrence after surgery for CD. Only colonic location and extent of the disease $>100 \mathrm{~cm}$ before surgery and the smoking status seem to be independent risk factors for increased risk of recurrence. Prophylactic medical therapy (below) has been shown to be effective in randomised controlled trials, confirmed by meta-analysis [ELla]. The age at onset of the disease, sex, duration of the disease, resection margins, or number of previous resections seem

Abbreviations: 5-ASA, mesalazine; AZA, azathioprine; $C D$, Crohn's disease; CDAl, Crohn's disease activity index; CsA, cyclosporin; ECCO, European Crohn's and Colitis Organisation; IBD, inflammatory bowel disease; IFX, infliximab; 6-MP, 6-mercaptopurine; UC, ulcerative colitis 
not to be risk factors for CD recurrence. ${ }^{13}$ 6-8 $12-52$ Evidence on the type of surgery and perforating (fistulating) behaviour are conflicting. The data are mainly against perforating disease as an independent risk factor. ${ }^{4}{ }^{6} 13$ 18-20 23313747 49-52 No validated predictive index has been developed.

\subsection{Diagnosis of postoperative recurrence}

\section{ECCO Statement $8 \mathrm{C}$}

Global physician assessment and acute phase reactants are used in clinical practice during follow up, but their accuracy has not been investigated [EL5, RG D]. The CDAl is an unreliable indicator of recurrence [EL2a, RGC]

\section{ECCO Statement 8D}

Ileocolonoscopy defines the presence and severity of morphologic recurrence and predicts the clinical course, so is recommended in all patients where recurrence is suspected [EL2a, RG B]

Diagnosis of POR may be based on clinical symptoms or endoscopic findings. Symptoms are not always easily distinguishable from other postoperative conditions (such as pain attributable to adhesional obstruction, calculi or dysmotility, and diarrhoea attributable to bile salt malabsorption or bacterial overgrowth). The CDAI has not been specifically validated in the postoperative setting, although a sensitivity of $30 \%$ and a specificity of $89 \%$ have been reported. ${ }^{69}$

Several studies have shown that colonoscopy is the most sensitive tool to report morphological recurrence. ${ }^{156}$ Endoscopic recurrence precedes clinical recurrence and severe endoscopic recurrence predicts a poor prognosis. ${ }^{1}$ Radiology and imaging (US, MR, CT) are used as surrogates for endoscopy..$^{70} 71$

\subsection{Medical prophylaxis}

Available data do not show a robust protective effect for any medical therapy. This remains a contentious area and it is

\section{ECCO Statement $8 \mathrm{E}$}

All patients should be encouraged to quit smoking after surgery for Crohn's disease [ELIb, RG B]

\section{ECCO Statement 8F}

Prophylactic treatment is recommended after small intestinal resection. The drug of choice is mesalazine $>2 \mathrm{~g}$ daily [ELla, RG B]. Imidazole antibiotics have been shown to be effective after ileocolic resection [ELla, RG A]. Other drugs including azathioprine/6-mercaptopurine should be considered as first line therapy in high risk patients [EL2b, RG C]

\section{ECCO Statement 86}

The start of prophylaxis is recommended within two weeks of surgery on the basis of pathophysiological considerations, although an early start has not been proved superior to later treatment [EL5, RG D]

\section{ECCO Statement $8 \mathrm{H}$}

The duration of prophylaxis should be at least two years [ELla, RG B]

important that all consensus statements are read in the context of the qualifying comments.

\subsubsection{Mesalazine (5-ASA)}

Prophylactic treatment to reduce the rate of POR remains controversial..$^{53}$ In the 1990s, several randomised controlled trials showed that oral 5-ASA, given early after surgery, was able to reduce the frequency of recurrence and to attenuate its severity. ${ }^{255} 56$ It may be argued that the data are flawed and that one of the original studies ${ }^{55}$ would have been negative had a two tailed $t$ test been used more appropriately for statistical analysis. Furthermore, the other early study ${ }^{2}$ had endoscopic end points and was not blinded. In 1997 a meta-analysis from Cammà et al ${ }^{12}$ showed that 5-ASA was superior to placebo for the prevention of clinical POR. This meta-analysis has been updated twice, the first ${ }^{58}$ after the publication in 2000 of a large European cooperative study, and then ${ }^{60}$ after the publication of a second study by the Gruppo Italiano per lo Studio del Colon e del Retto (GISC ${ }^{59}$ ). The GISC study compared 5-ASA $2.4 \mathrm{~g}$ with $4.0 \mathrm{~g}$ did not include a placebo control group and failed to show a benefit for either clinical or endoscopic recurrence. The European cooperative study ${ }^{57}$ showed that 5-ASA $4.0 \mathrm{~g} /$ day did not significantly affect clinical overall POR. It included, however, a substantial subgroup of 124 patients who had had isolated resection of small bowel CD who did benefit from treatment with 5-ASA $4.0 \mathrm{~g} /$ day compared with placebo. The updated meta-analysis ${ }^{58}$ included this large European trial and remained in favour of treatment with 5-ASA. Subsequently, the 206 patients in the negative GISC study ${ }^{59}$ permitted a further updated meta-analysis ${ }^{60}$ of six studies ${ }^{25-575961}$ in a total of 1141 patients. The results showed that 5-ASA reduced the rate of endoscopic recurrence by $18 \%$, which is a clinically relevant result $(\mathrm{NNT}=5.5)$. For clinical recurrence the data still remain in favour of 5-ASA, with an overall risk difference of $15 \% \quad(\mathrm{NNT}=6.6)$, which is also clinically relevant, although the meta-analysis has not yet been fully published. Nevertheless, given 5-ASA's limited effect, no prophylactic treatment may be an option in some asymptomatic or low risk patients.

\subsubsection{Antibiotics}

\section{Metronidazole}

Metronidazole given for three months after surgery significantly reduced the incidence of severe endoscopic recurrence at one year follow up, although the effect was not sustained beyond 12 months. ${ }^{62}$ Clinical recurrence was also delayed, which was the most important effect. The risk difference $(18 \%)$ on intention to treat analysis in this study of 60 patients was comparable to the overall risk difference (15\%) in the meta-analysis of 5-ASA including 1141 patients.$^{60}$ On the basis of this finding, metronidazole may be considered for the prevention of POR, but in clinical practice is rarely used because of side effects during long term treatment.

Another nitroimidazole antibiotic, ornidazole $1 \mathrm{~g} /$ day, has also shown efficacy in the prevention of POR in 80 patients with $\mathrm{CD}$ at one year follow up, although was not well tolerated, similar to metronidazole. ${ }^{63}$ This study confirmed a close relation between the development of severe endoscopic lesions in the neoterminal ileum after surgery and subsequent development of clinical recurrence. 


\subsubsection{Azathioprine/6-mercaptopurine}

The thiopurines azathioprine (AZA) and 6-mercaptopurine (6-MP) are widely recommended for reducing the risk of POR after surgery for complex CD. The data are, however, open to interpretation. There was a trend for 6-MP $50 \mathrm{mg} /$ daily to be more effective than placebo and 5-ASA in preventing clinical POR. ${ }^{64}$ The results of this study had originally been presented as an abstract six years previously. ${ }^{65}$ Observed rates of endoscopic recurrence (defined as Rutgeerts endoscopy score $>1)$ at two years for placebo, 5-ASA, and 6-MP were 64\%, $63 \%$, and $43 \%$, respectively, but the study had two main drawbacks. Firstly, the clinical recurrence rate (based on physician global assessment) in the placebo group at two years was higher than the endoscopic recurrence, which is unique. Secondly, of 131 patients enrolled only 57 completed the trial. The final analysis was therefore conducted on 57 patients, divided into three groups. Although the results of this study do not provide robust data in favour of 6-MP over placebo or 5-ASA, a further prospective study randomised 142 patients to receive AZA $2 \mathrm{mg} / \mathrm{kg} /$ day or 5 -ASA $3 \mathrm{~g} /$ day for 24 months. This showed comparable rates of clinical (OR 2.04, CI 0.89 to 4.67) and surgical recurrence. Subgroup analysis showed a favourable effect of AZA for patients who had had a previous resection (OR $4.83,95 \%$ CI 1.47 to 15.8 ). ${ }^{74}$

\subsection{Other therapy}

In controlled trials there is no evidence that probiotics, ${ }^{66}$ fishoil ${ }^{67}$ or interleukin 10 therapy $^{68}$ are effective at preventing POR after surgery for CD.

\subsection{Management}

\section{ECCO Statement 81}

In asymptomatic patients, if colonoscopy is performed and mild lesions are found no change of therapy is recommended [EL1b, RG D]. Severe lesions are associated with high risk of clinical recurrence. Starting therapy with AZA/6MP may be considered, although its efficacy has not been firmly established in this setting [EL2b, RG D]

Management to reduce the risk of POR differs whether symptoms or endoscopic lesions are present. Not all gastroenterologists routinely perform colonoscopy after ileocaecal resection of $\mathrm{CD}$. In asymptomatic patients with mild endoscopic lesions, there are no data showing the need to change therapy. In asymptomatic patients with severe endoscopic lesions, AZA therapy has been reported to be effective at healing the lesions and improving outcome. ${ }^{72} 73$

\section{ECCO Statement 8J}

Symptomatic patients should have a colonoscopy and be treated as any other patient with active disease [EL5, RG D]

Symptomatic patients are usually treated in the same way as those with active disease who have not had surgery.

\section{ECCO Statement $8 \mathrm{~K}$}

The risk of relapse does not seem to correlate with the type of operation, so patients undergoing conservative surgery should be treated in the same way as those who have an extensive resection [ELIb, RG B]
The extent of resection has not been shown to influence the risk of recurrence, but the decision on postoperative prophylaxis is best governed by what is at stake (proctectomy, short bowel syndrome) in the event of a further relapse. For patients who have had conservative surgery for $C D$, the risk of clinical relapse is comparable whether patients are treated by AZA or 5-ASA. ${ }^{64}$ However, in a subgroup analysis, AZA was significantly better than 5-ASA at preventing clinical relapse in patients who had had previous intestinal resections. ${ }^{74}$

\subsection{DIAGNOSIS AND MANAGEMENT OF FISTULATING CD \\ 9.1 Introduction}

Fistulating CD includes fistulas arising in the perianal area, together with those communicating between the intestine and other organs or the abdominal wall. The main aspects to be taken into account when planning a strategy for the management of CD fistulas are:

- Locate the origin of the fistula and its anatomy

- Evaluate the originating intestinal loop (inflammation or stenosis)

- Identify or exclude local sepsis (abscess)

- Determine which organs are affected and their contribution to systemic symptoms or impairment of the quality of life

- Assess the nutritional status of the patient

Most emphasis is placed on perianal fistulas complicating $\mathrm{CD}$, as these are most common and supported by the largest body of literature. Nevertheless, the greatest limiting factor for this consensus was the scarce number of controlled data regarding combined medical and surgical management. Consequently this section includes more details on expert opinion (consensus views) quantified by the pre-consensus questionnaire, as this may help define current practice.

\subsubsection{Perianal fistulas}

In a series of 202 consecutive patients with CD at a teaching hospital up to $54 \%$ had suffered perianal complications. ${ }^{75}$ In population based studies, ${ }^{76}{ }^{77}$ the occurrence varies between $21 \%$ and $23 \%$. The cumulative frequency was $12 \%$ at 1 year, $15 \%$ at 5 years, $21 \%$ at 10 years and $26 \%$ at 20 years. The prevalence varies according to disease location. Perianal fistulas were noted in $12 \%$ with isolated ileal disease, $15 \%$ with ileocolonic disease, $41 \%$ with colonic disease and rectal sparing, and $92 \%$ with colonic disease involving the rectum. ${ }^{76}$ Perianal disease often precedes or appears simultaneously with intestinal symptoms. ${ }^{76} 77$

\subsubsection{Non-perianal fistulas}

This includes fistulas communicating with other viscera (urinary bladder, vagina), loops of intestine (enteroenteral fistulae), or the abdominal wall (enterocutaneous fistulas). There is a notable lack of controlled data in this field.

\subsection{Diagnosis of perianal fistulas}

\subsubsection{Initial diagnostic approach}

The diagnostic approach is a crucial aspect in the management of fistulating perianal $C D$, as the findings influence the

\section{ECCO Statement 9A}

Pelvic MRI should be the initial procedure because it is accurate and non-invasive, although it is not needed routinely in simple fistulae [EL2b, RG B]. If MRI is contraindicated then the recommended procedure for complex fistulas is examination under anaesthetic (EUA) [EL5, RG D] 


\section{ECCO Statement 9B}

Examination under anaesthetic is considered the gold standard only in the hands of an experienced surgeon. It may permit concomitant surgery, but care should be taken to obtain appropriate informed consent of the patient, as unexpected findings may preclude this [EL5, RG D]

\section{ECCO Statement $9 \mathrm{C}$}

Anorectal ultrasound requires expertise, has technical limitations and may be difficult or impossible to perform because of local complications (abscesses or stenosis) [EL2b, RG B]. Fistulography is not recommended [EL3, RG C]

\section{ECCO Statement 9D}

As the presence of concomitant rectosigmoid inflammation has prognostic and therapeutic relevance, proctosigmoidoscopy should be used routinely in the initial evaluation [EL2b, RG B]

therapeutic strategy. Various tools have been described, including examination under anaesthetic (EUA), fistulography, and imaging by endoscopic ultrasonography or magnetic resonance. As inflammation in the affected bowel segment determines whether medical therapy is combined with surgical drainage, endoscopy is best combined with anatomical definition of the fistulous track.

EUA is reported to be the most sensitive, with an accuracy of $90 \% .{ }^{77}$ It has the advantage of permitting concomitant surgery, but care must be taken to obtain appropriate informed consent before the operation in case of unexpected findings. When perianal pain is present an abscess is almost always the cause. If an abscess is present or suspected, a prompt EUA is the procedure of choice to prevent the destructive effective of pus under pressure. It should not be delayed until an MR has been performed, unless the MR scan is immediately available. Nevertheless, MRI has an accuracy of $76 \%-100 \%$ compared with EUA $^{78-80}$ for fistulas and may provide additional information. Anorectal ultrasound has an accuracy of $56 \%-100 \%$, especially when performed by experts in conjunction with hydrogen peroxide enhancement. ${ }^{81-83}$ Any of these methods can be combined with the endoscopy to assess the presence or absence of inflammation in the rectosigmoid colon. Anecdotal experience indicates that treatment of fistulas is unsuccessful without treatment of underlying, active disease.

\section{Consensus views}

The preferred initial diagnostic approach was MRI (82\% always or usually), plus proctosigmoidoscopy (75\% always or usually). Depending on the circumstances and availability, $44 \%$ expressed a preference for EUA and 38\% for endoanal ultrasonography for initial diagnosis.

\subsubsection{Classification of perianal fistulas}

Various classifications have been proposed, either relating fistulas to the anorectal ring (high or low), or in more precise anatomical terms where the external sphincter is the

\section{ECCO Statement 9E}

There is no consensus for classifying perianal fistulas in CD. In clinical practice most experts use a classification of simple or complex. From the surgical point of view Parks' classification is more descriptive and can influence surgical decisions, but it is complicated to use in routine practice [EL5, RG D]

reference point, described by Parks. ${ }^{84}$ A more empiric and easier classification into simple and complex fistulas has been proposed. ${ }^{85}$ This includes the physical inspection of the area to detect fistulous connections, strictures, and abscesses, together with the endoscopic evaluation of the rectosigmoid area for the presence or absence of macroscopic inflammation.

\section{Consensus views}

Classification into simple and complex perianal fistulas based upon clinical and endoscopic features ${ }^{85}$ was recommended by $75 \%$ and the Parks classification ${ }^{84}$ by $25 \%$ who expressed an opinion. Other systems were not often used, although the perianal disease activity index (PDAI ${ }^{86}$ was used for overall assessment of perianal disease by $34 \%$ in some circumstances.

\subsubsection{Influence of the treatment strategy on the diagnostic approach \\ Consensus views}

Most (66\%) consider that the medical or surgical treatment strategy should not influence the diagnostic approach. When surgery or medical therapy are planned, techniques designed to define the anatomical distribution of the fistulas are considered mandatory.

9.2.4 Progression from simple to complex disease in the short to mid-term

There are no objective data.

\section{Consensus views}

Most $(72 \%)$ consider that simple fistulas rarely progress to complex fistulas in the short to mid-term (two years), although were this possible it would influence the therapeutic approach. Data are needed.

\subsection{Treatment of fistulating disease}

9.3.1 Simple perianal fistulas

\section{ECCO Statement 9F}

For simple perianal fistulas it is important to know if they are symptomatic. If they are not, nothing has to be done. Only when simple fistulas are symptomatic are the options of noncutting Seton or fistulotomy recommended [EL3, RG D]. Antibiotics, metronidazole (750-1500 mg/day), or cyprofloxacin (1000 mg/day), should be added [EL3, RG D]

\section{Consensus views}

Almost all used antibiotics as the first medical therapy option, AZA/6-MP as the second option, and infliximab as the third option (evidence below). However, when a simple perianal fistula is symptomatic in CD, opinion favours a combined medical and surgical strategy. Neither cyclosporin (CsA) nor tacrolimus were favoured as a fourth option. 


\subsubsection{Complex perianal disease}

\section{ECCO Statement 96}

Antibiotics and/or azathioprine/6-mercaptopurine should be used as the first choice of therapy for complex perianal Crohn's disease in combination with surgical therapy despite a lack of clinical trials [EL4, RG D]. The presence of a perianal abscess should be ruled out and if present it should be drained. Infliximab should be used as a second line treatment [ELIb, RG B]

\section{ECCO Statement $9 \mathrm{H}$}

Seton placement should be recommended [EL4, RG D]. A diverting ostomy can rapidly restore the quality of life in highly symptomatic patients [EL4, RG D]

\section{Consensus views}

Most initially used the same type of medical treatment options as for simple perianal disease. However, there was less agreement on the sequence, especially for antibiotics as the first option, as earlier use of infliximab was generally recommended. Abscesses should be sought and surgical drainage must be performed if present.

\subsubsection{Medical therapy}

\section{Metronidazole and/or ciprofloxacin}

There are no randomised controlled trials (RCTs) on the effect of metronidazole and/or ciprofloxacin in perianal CD. Uncontrolled case series are the only basis for using these agents in these patients. ${ }^{87-90}$ Antibiotics are effective for improving symptoms of the disease, but rarely induce complete healing. Exacerbation is the rule when these drugs are withdrawn.

\section{AZA/6-MP}

There are also no RCTs assessing the effect of AZA or 6-MP on the closure of perianal fistulas as primary end point in CD. Data favouring the use of these drugs come from a metaanalysis of five RCTs where perianal fistula closure was assessed as a secondary end point, ${ }^{91}$ in addition to uncontrolled case series. In this context, AZA and 6-MP seem to be effective in both closing and maintaining closure of perianal fistulas. ${ }^{92}$

\section{Infliximab}

Infliximab was the first agent shown to be effective in an RCT for inducing closure of perianal fistulas and for maintaining this response for one year. For treatment of simple or complex perianal fistulas, $5 \mathrm{mg} / \mathrm{kg}$ infusions at weeks 0,2 , and 6 induced complete closure (cessation of all drainage on two visits one month apart) in 17 of 31 (55\%) of cases. ${ }^{93}$ The ACCENT II trial confirmed this initial response $(69 \%$, or 195 of 306 at 14 weeks), and randomised responders to receive $5 \mathrm{mg} / \mathrm{kg}$ every eight weeks, or placebo). ${ }^{94}{ }^{95}$ At week 54, 33 of $91(36 \%)$ on infliximab had complete closure compared with 19 of $98(19 \%)$ receiving placebo $(p=0.009)$. Response, defined as $>50 \%$ closure on clinical assessment, was seen in $46 \%$ receiving infliximab $(23 \%$ placebo, $p=0.01)$. Maintenance infliximab reduces hospitalisation and surgery. ${ }^{96}$ These effects have been confirmed in clinical practice by several uncontrolled case series. ${ }^{97}{ }^{98}$ There are no data on the effect of infliximab on simple Crohn's perianal fistulas.

\section{CsA}

The only data on intravenous CsA in perianal CD come from several uncontrolled case series which, as a whole, include fewer than 100 patients. ${ }^{99}$ Patients who responded were converted to oral CsA, but response was rapidly lost on drug withdrawal.

\section{Tacrolimus}

Uncontrolled case series showed that tacrolimus may be effective for perianal $\mathrm{CD} .{ }^{100-103} \mathrm{~A}$ subsequent small, placebo controlled trial showed that oral tacrolimus $0.2 \mathrm{mg} / \mathrm{kg} /$ day was better than placebo at improving (closure of at least $50 \%$ of fistulas), but not at inducing remission (closure of $100 \%$ of fistulas), in perianal CD after four weeks. ${ }^{104}$

\section{Other treatments}

Case reports and uncontrolled case series have reported benefit, from enteral or parenteral nutrition, mycophenolate mofetil, methotrexate, thalidomide, granulocyte colony stimulating factor, and hyperbaric oxygen, but they are not recommended for standard practice. ${ }^{86}$

\subsubsection{Surgical procedures for perianal CD}

Surgical treatment is sometimes necessary for simple fistulas, but is always necessary for complex perianal disease. It includes abscess drainage, fistulotomy, and Seton placement, according to the symptoms caused by the location and complexity of the fistulas. A diverting ostomy or proctectomy may be necessary for severe disease refractory to medical therapy. Fistulectomy and fistulotomy should not be performed, because of the risk of incontinence and later need of proctectomy.

\subsubsection{Monitoring the therapeutic response}

\section{ECCO Statement 91}

In evaluating the response to medical or surgical treatment in routine practice, clinical assessment (decreased drainage) is usually sufficient [EL2b, RG D]. In the setting of clinical trials, MRI alone or in combination with clinical assessment is now considered mandatory [EL2b, RG D]

\section{Consensus views}

Most report using more that one method. Clinical assessment, as described by Present, ${ }^{93}$ which defines cessation of drainage despite gentle pressure in $>50 \%$ fistulas after treatment, or MRI were preferred by 59 and $53 \%$ respectively. Some $(34 \%)$ use the PDAI $^{86}$ alone or in combination with other techniques. ${ }^{83}$ Endoanal ultrasound was used by $<20 \%$.

\subsection{Continuing therapy for perianal CD}

\section{ECCO Statement 9J}

AZA/6-MP, with or without long term Seton drainage, should be used as maintenance therapy [EL2b, RG C]. If this fails, infliximab should be added for induction and maintenance for at least one year [EL1b, RG A]

There are no data on the effect of AZA/6-MP as maintenance therapy for fistulas after induction with infliximab, or during 
infliximab maintenance therapy. Around $75 \%$ of patients in the ACCENT II trial were already taking AZA/6-MP ${ }^{94}{ }^{96}$ before recruitment, but this medication was continued together with infliximab in only $30 \%$. This implies that although infliximab maintained longer fistula closure than placebo in this trial, it occurred with AZA/6-MP as background therapy in some cases. ${ }^{94}$ An additional reason for thiopurine therapy is to reduce the development of anti-infliximab antibodies. ${ }^{105}$ Nevertheless for perianal disease, it is only maintenance therapy with infliximab that has been shown to reduce hospitalisation and surgery. ${ }^{96}$

\section{Consensus views}

More than $90 \%$ believe that maintenance therapy after successful infliximab induction is mandatory. The preferred drugs were AZA/6-MP or infliximab (in this order), with infliximab either as scheduled re-treatment every eight weeks, or as required in conjunction with thiopurines.

9.4.1 Therapeutic approach in the event of infliximab failure

\section{ECCO Statement $9 \mathrm{~K}$}

In the event of infliximab failure, the use of azathioprine/6mercaptopurine or methotrexate, with antibiotics as adjunctive treatment, is the first therapeutic choice [EL5, RG D]. Depending on the severity of the disease, a diverting ostomy can be performed later, or proctectomy as the last resort [EL5, RG D]

\section{Consensus views}

In this event, surgical treatment (alone or combined with medical therapy) was suggested by about 50\%. Among medical treatments, the preferred drugs were AZA/6-MP and MTX although some favoured a higher dose of infliximab.

\subsubsection{Surgical intervention in conjunction with} infliximab treatment

There is concern about infliximab treatment in the presence of undetected perianal sepsis. Surgery (by EUA) for perianal disease includes abscess drainage, fistulotomy, and Seton placement, and may be important to optimise therapeutic results as well as avoiding septic complications.

\section{Consensus views}

Most $(78 \%)$ thought that it was only necessary in the presence of an abscess and $25 \%$ considered it mandatory (with the overlap representing those who felt an abscess could only be reliably excluded by EUA; note diagnosis section above). None thought that it should not be done. When asked if the surgical "toilette" should be performed before or after infliximab most $(78 \%)$ believed that it should be done before.

\subsection{Management of non-perianal fistulating CD}

There are no RCT on the effect of medical treatment for nonperianal fistulating $\mathrm{CD}$, other than the subgroups of the ACCENT II trial. Less than $10 \%$ of the patients in the ACCENT II trial receiving infliximab therapy had abdominal enterocutaneous fistulas. ${ }^{94}$ For the 25 (of 282) patients with rectovaginal fistulae in the ACCENT II trial, infliximab was only modestly effective (45\% closure at week 14$).{ }^{95}$

\subsubsection{Enterogynaecological fistulas}

\section{ECCO Statement 9L}

Low anal-introital fistula may be almost asymptomatic and not need surgical treatment [EL5, RG D]

\section{ECCO Statement $9 M$}

If the patient has a symptomatic fistula, surgery is usually necessary (including diverting ostomy) [EL5, RG D]. Rectovaginal fistulas failing conservative treatment should have surgery with an advancement flap and/or divertingostomy if they are associated with unacceptable symptoms [EL5, RG D]. Intestinal small bowel or sigmoid-gynaecological fistulas can usually be treated with resection of the diseased bowel segment [EL5, RG D]

\subsubsection{Enterovesical fistulas}

\section{ECCO Statement $9 \mathrm{~N}$}

Surgery is the preferred approach for enterovesical fistulas [EL5, RG D]. Only in high risk patients (after multiple operations and lor severely shortened bowel), should medical therapy be the first option [EL5, RG D]

\subsubsection{Recommendations for enterocutaneous fistulas}

\section{ECCO Statement 90}

Post-surgical enterocutaneous fistulas should initially be treated conservatively, with nutritional support and anatomical definition [EL5, RG D]. Surgery after an interval is appropriate once nutrition is restored. Primary enterocutaneous fistulse can be treated either surgically (by resecting the diseased bowel segment) or medically [EL5, RG D]

\subsection{IN CHILDREN AND ADOLESCENTS: DIAGNOSIS AND TREATMENT \\ 10.1 Introduction}

The incidence of $\mathrm{CD}$ in children and adolescents is about 3 per 100000 , and has risen during the past decade. ${ }^{106-111}$ In about $25 \%$ of all patients, the disease presents before the age of 18 years, and even in very young children (age $<2$ years) $\mathrm{CD}$ is becoming more common. Certain features are unique to paediatric $\mathrm{CD}$ as compared with adult onset disease. One feature is growth failure, which is present at diagnosis in $10 \%-40 \%$ of affected children. ${ }^{112}$ Less obvious, but nevertheless clinically important, are differences in clinical presentation that may reflect different disease locations in children compared with in adults. Abdominal pain is the most frequent symptom in children with $\mathrm{CD}^{113}$ whereas adults tend to present most often with diarrhoea. Adult phenotypes of CD (such as the Vienna classification of inflammatory, stricturing or fistulating $)^{114}$ may not be useful for children, who have predominantly inflammatory disease. A family history of IBD is often present in children $(26 \%-$ $42 \%),{ }^{115}$ and preliminary studies suggest that genetic factors 
may be of more importance in paediatric $C D$, compared with adults. ${ }^{116}$

\subsection{Diagnosis}

\section{ECCO Statement 10A}

Initial investigation of a child suspected of CD should consist of colonoscopy (including terminal ileal intubation) with multiple biopsies [EL2b, RG B], and upper GI endoscopy with multiple biopsies [EL2b, RG B]. In addition to endoscopy, small bowel radiology (follow through or enteroclysis) should be performed [EL2b, RG B]

The IBD working group of the European Society of Paediatric Gastroenterology Hepatology and Nutrition (ESPGHAN) has reached a consensus on the diagnosis of IBD in children, which have been summarised as the "Porto Criteria". ${ }^{117}$ This group feels it is essential to establish a diagnosis of the type of disease, as well as to determine severity, localisation, and extent of the disease, before treatment is started. The ECCO Consensus agrees that all children suspected of CD should have a complete examination at the time of diagnosis.

Evidence from the literature supporting the colonoscopy with ileal intubation, and not simply sigmoidoscopy, is provided by retrospective cohort studies. ${ }^{113}$ 118-124 $^{\text {Additional }}$ upper endoscopy is advised on the basis of both retrospective and prospective studies showing that histology of the upper GI tract may confirm a diagnosis of CD that would otherwise have been missed in $11 \%$ to $29 \%$ of cases. ${ }^{125-128}$ Small bowel radiology should be part of the initial investigation for the following reasons: firstly, the small bowel may be abnormal even though the terminal ileum is normal. ${ }^{129}{ }^{130}$ In addition, small bowel follow through (SBFT) or enteroclysis with intubation of the duodenum with barium contrast will give information on extent and possible complications of small bowel CD including strictures or internal fistulas. The presence of small bowel strictures will affect therapeutic management, as inactive short segment stenosis may need resection. Transabdominal ultrasound is not a substitute, but may be used as for initial assessment of symptoms or to look for complications. Endoscopy in children is best carried out under general anaesthesia: it is safe and preferred for ethical reasons. ${ }^{131} 132$

\subsection{Treatment}

\subsubsection{General}

The medical treatment of CD in children is shifting towards a more aggressive approach at presentation of the disease. Immunomodulators such as AZA are being introduced early. Evidence from clinical trials in children with CD is scarce, and treatment decisions are often based on extrapolation from clinical trials in adults. However, some good quality clinical trials have been performed during the past five years, providing the basis for these guidelines.

Initial treatment of $\mathrm{CD}$ in children depends on disease severity and localisation. In mild disease, 5-ASA is often started although there is not one randomised clinical trial of 5-ASA in children. In moderate to severe disease, corticosteroids or nutritional treatment are primary treatment.

\subsubsection{Induction therapy}

Evidence from a meta-analysis of trials comparing efficacy of corticosteroids and nutritional treatment ${ }^{133}$ show that both options are effective ( $80 \%$ remission induction), but nutritional treatment is preferred because of lack of side effects and a beneficial effect on growth in children. Nutritional

\section{ECCO Statement 10B}

Both enteral nutrition (EN) and corticosteroids are effective for induction of remission (although EN lacks side effects), irrespective of disease activity or location [ELla, RG A]. Enteral nutrition seems to be more effective in newly diagnosed $C D$ patients. Elemental enteral formula is not more effective compared to polymeric formula feeds [EL3, RG C]

treatment is probably more effective in new onset disease than in recurrent disease, independent of disease severity or localisation. There is insufficient evidence to suggest that elemental (or oligomeric) formula is better than nonelemental (polymeric) formula feed.

\section{ECCO Statement 10C}

Budesonide is effective and favoured over prednisolone in mild to moderate active ileocaecal CD because of significantly fewer side effects [ELIb, RG A]

In children with mild to moderately active ileocaecal CD, two randomised controlled trials supported the use of budesonide (controlled ileal release), which was less effective than prednisolone, but with significantly fewer side effects. ${ }^{134} 135$

\section{ECCO Statement 10D}

The role of mesalazine for inducing remission in children with active $C D$ is unclear [EL2b, RG B]

\subsubsection{Maintenance therapy}

\section{ECCO Statement 10E}

Corticosteroids are not to be used as maintenance treatment [EL5, RG D]

In the maintenance treatment of paediatric $C D$, corticosteroids are not to be used because of their negative effect on growth and bone mineralisation. In addition, studies in adults have shown that long term treatment with corticosteroids does not maintain remission of disease.

\section{ECCO Statement 10F}

The role of mesalazine in maintaining remission in paediatric $C D$ is unclear [EL2b, RG B]

The role of 5-ASA as maintenance treatment is unclear, as no studies are available in children. Extrapolation from the adult literature suggests that 5-ASA has no advantage over placebo. However, mainly because of its perceived lack of side effects, 5-ASA is still often used in children who present with mild disease. 


\section{ECCO Statement $10 \mathrm{G}$}

Azathioprine or 6-MP is useful for the maintenance of remission. Early introduction should be considered after corticosteroid induction as a part of the treatment regimen in newly diagnosed paediatric patients with CD [EL1b, RG A]

\section{ECCO Statement $10 \mathrm{H}$}

Methotrexate is effective in maintaining remission in patients resistant or intolerant to azathioprine or 6-mercaptopurine [EL4, RG C]

The most effective drugs used to maintain remission seem to be the thiopurines AZA and 6-MP. Early introduction at the time of remission-induction has been shown to result in a valuable corticosteroid sparing effect, in addition to significant prolongation of the duration of remission. ${ }^{136}$ Methotrexate is an alternative to AZA or 6-MP if these drugs are not tolerated or are ineffective. ${ }^{137}$

\subsubsection{Refractory disease}

\section{ECCO Statement 10I}

Infliximab is effective for induction of remission in refractory paediatric Crohn's disease, including refractory fistulating disease [EL4, RG C]

In children with refractory $\mathrm{CD}$ (unresponsive to corticosteroids, corticosteroid dependent, or complicated by corticosteroid toxicity despite AZA or 6-MP treatment), infliximab has been shown to induce clinical remission effectively and safely in several open label studies and retrospective series. ${ }^{138-149}$ At this moment, the results of a multicentre RCT comparing two regimens of infliximab maintenance treatment (every eight weeks compared with every 12 weeks) are awaited.

\section{ECCO Statement 10J}

Elective surgery is indicated in pre-pubertal children with growth failure, especially when disease is limited to the terminal ileum [EL4, RG C]

Surgical treatment is indicated in localised (stricturing), treatment-resistant ileocaecal disease and should be considered at an early stage in the presence of growth failure, as the "moment of opportunity" might have lapsed once puberty has started. ${ }^{150-154}$

\subsection{Supportive management}

\section{ECCO Statement 10K}

Psychosocial support should be given to patients and their families [EL4, RG C]

Special consideration should be given to the psychosocial support of children and adolescents with CD for several reasons: psychiatric problems such as depression occur more frequently in this population ${ }^{155}$ and quality of life may improve when adequate coping skills are taught. ${ }^{156}$

\section{ECCO Statement 10L}

Growth and pubertal development should be recorded at diagnosis and during the course of disease. Growth failure and pubertal delay should be treated [EL4, RG C]

Lastly, growth failure is a unique complication of paediatric inflammatory bowel disease (IBD) and needs to be addressed separately. Growth failure is caused by a combination of insufficient intake of calories, increased losses, and ongoing inflammation. When a child fails to grow, treatment is inadequate. In these paediatric patients, treatment should be intensified and adequate intake of calories ensured.

\subsection{Conclusions}

In summary, $C D$ in children should be diagnosed by ileocolonoscopy and upper endoscopy (both with multiple biopsies) and small bowel follow through. For treatment of active disease, nutritional treatment is a good alternative to corticosteroids. Maintenance treatment is aimed at avoidance of corticosteroids, by early introduction of AZA or 6-MP. At the present time infliximab is reserved for induction of remission of refractory $\mathrm{CD}$, including fistulating disease.

\subsection{THE MANAGEMENT OF PREGNANCY IN CD 11.1 Introduction}

CD often occurs in young adults, and therefore caring for patients who are also pregnant is not uncommon. It has been estimated that around $25 \%$ of female patients conceive after the diagnosis of CD. Maintaining adequate disease control is crucial for both maternal and fetal health, and should be performed in a multidisciplinary way, involving both gastroenterologists and obstetricians.

\subsection{Fertility in $C D$}

\section{ECCO Statement 11A}

Crohn's disease does not seem to affect fertility when the disease is inactive [EL3b, RG B]; however active disease leads to reduced fertility [EL3b, RG B]. Female patients who undergo surgery are at risk for impaired tubal function [EL3b, RG B]. In male patients rectal excision may lead to impotence or ejaculatory problems; however there is no comparison with the general population [EL4, RG C]. Sulfasalazine therapy causes infertility (reversible) in male patients because of changes in semen quality [EL3b, RG B]

Patients with quiescent $\mathrm{CD}$ are as fertile as the general population. ${ }^{157-159}$ Patients with IBD have fewer children than the general population, but this is partly because of voluntary childlessness. Active CD reduces fertility by several mechanisms, including inflammation involving the fallopian tubes and ovaries, perianal disease causing dyspareunia, ${ }^{159-162}$ and previous surgical intervention. ${ }^{163-171}$ Sulfasalazine therapy (but neither other 5-ASA compounds nor AZA) causes a reversible decrease in sperm motility and count in male patients. The effect is dose related and it is unaffected by supplemental folic acid. ${ }^{172-177}$ 


\subsection{Influence of disease activity on the course and outcome of pregnancy}

\section{ECCO Statement 11B}

It is advisable to strive for clinical remission before conception. Flares are best treated aggressively to prevent complications [EL3a, RG B]. Active disease is a risk for preterm delivery and low birth weight [EL3a, RG B]. Insufficient data exist about maternal morbidity and fetal mortality at surgery

Quiescent CD has minimal effects on the course and outcome of pregnancy. ${ }^{158} 161178$ Active CD, either at the time of conception or during pregnancy, has been shown to increase the incidence of foetal loss, stillbirths, preterm delivery, low birth weight, and developmental defects. Importantly, it should be emphasised that this seems to be related to disease activity rather than medications used during pregnancy. ${ }^{160} 161179180$ Fetal mortality is very high if surgery is required, where abortion-stillbirth rates are as high as $18 \%-$ $40 \%{ }^{181}$ Careful obstetric and medical follow up during pregnancy is prudent, especially in the third trimester. ${ }^{157} 182$

\subsection{The influence of pregnancy on the course of CD}

\section{ECCO Statement $11 C$}

If conception occurs at a time of quiescent disease the risk of relapse is the same as in non-pregnant women [EL5, RGD]. If conception occurs at a time of active disease, two thirds have persistent activity and of these two thirds deteriorate [EL3b, RG $B$ ]. There is a negative association between the number of pregnancies and surgical interventions [EL4, RG C]. Both clinical activity and surgical interventions decline with pregnancy and parity. Nutritional status also influences parity [EL4, RG C]

When conception occurs during a period of remission, about a third of patients relapse during pregnancy, ${ }^{180}$ which is similar to that expected in non-pregnant CD patients over a period of nine months. On the other hand, if conception occurs at a time of active disease, two thirds have persistent activity and of these, two thirds will deteriorate. ${ }^{158}{ }^{183}{ }^{184}$ This underscores the importance of advising patients to conceive at a time when disease is in remission. Two studies have suggested that pregnancy influences the overall course of IBD, ${ }^{185} 186$ because as parity increases, the need for surgical intervention decreases. Patients with a previous pregnancy require fewer resections and the interval between operations tends to be longer when compared with nulliparous women with $\mathrm{CD}$. Mothers with $\mathrm{CD}$ also have a lower relapse rate in the year after pregnancy, compared with the year before pregnancy. Pregnancy has an effect on the immune system, which may contribute to these findings. ${ }^{187}$

\subsection{Mode of delivery}

The mode of delivery should primarily be dictated by obstetric necessity, but the decision should be combined with the gastroenterologist to avoid perianal complications. The standard practice is vaginal delivery for women with quiescent or mild disease. ${ }^{188}$ Caesarean section is recommended

\section{ECCO Statement $11 E$}

The mode of delivery should primarily be governed by obstetric necessity and indication, but also in conjunction with the gastroenterologist. Uncomplicated CD patients without perianal disease should deliver vaginally after obstetric evaluation has been performed [EL4, RG C]. Caesarean section should be preferred in active perianal disease [EL4, RG C]. For inactive perianal disease, caesarean section may be considered [EL5, RG D]. An ileoanal pouch in CD patients is regarded as an indication for caesarean section [EL4, RG C]. Colostomy/ileostomy patients can deliver vaginally [EL4, $R G$ C]. If there is an increased obstetric risk, a caesarean section should be performed. However caesarean section in this setting carries an increased risk of complications [EL4, RG C]. Episiotomy should probably be avoided, but is better than a spontaneous uncontrolled laceration. However there are discrepancies in the literature [EL4, RG C]

in active perianal disease. ${ }^{188}$ Ileo-pouch-anal anastomosis in CD patients is also regarded as an indication for caesarean section, because of a theoretically increased risk of damage to the anal sphincter ${ }^{167}{ }^{189-192}$ despite a lack of evidence. Patients with a colostomy or ileostomy can deliver vaginally, ${ }^{192}$ but if the obstetric risk is increased for other reasons, there should be a low threshold for caesarean section. Episiotomy should be avoided if possible, because a high rate of perianal involvement has been reported, but is better than an uncontrolled laceration. ${ }^{193}$

\subsection{Surgery during pregnancy}

\section{ECCO Statement $11 F$}

Indications for surgery in pregnant CD women are the same as for non-pregnant patients: obstruction, perforation, haemorrhage, and abscess. In the severely ill patient, continued illness is a greater risk to the foetus than surgical intervention [EL5, RG D]

Indications for surgery in pregnant CD women are obstruction, perforation, haemorrhage, or abscess and are no different to those for non-pregnant women. ${ }^{194-197}$ In severely ill patients, continued illness is a greater risk to the fetus than surgical intervention. ${ }^{194}$ There are only few case reports of surgery in CD. ${ }^{195}$ Procedures have included proctocolectomy, hemicolectomy, segmental resection, and ileostomy. A temporary ileostomy is generally preferred, to reduce the risk of postoperative complications after primary anastomosis. ${ }^{197}$

\subsection{Medical treatment during pregnancy}

Proactive maintenance of quiescent disease is preferred. Benefit ratio of medication should be considered when counselling pregnant CD patients. In active disease during pregnancy the Food and Drug Administration (FDA) pregnancy categories, $\mathrm{ABCDX}$, reflect this cautious approach (tables 11.1, 11.2). The drug description notice always emphasises risks and side effects.

The greatest risk to mother and fetus during pregnancy is active disease, and not the medication used to treat it. In general, pharmacological treatment for active disease during pregnancy is the same as for non-pregnant women. 
Table 11.1 Food and drug administration (FDA) categories

$\begin{array}{ll}\text { A } & \text { Controlled studies show no risk } \\ \text { B } & \text { No evidence of risk in humans } \\ \text { C } & \begin{array}{l}\text { Risk cannot be ruled out, animal studies showed adverse effects } \\ \text { on fetus }\end{array} \\ \text { D } & \begin{array}{l}\text { Positive evidence of risk in humans, risk/benefit ratio should be } \\ \text { considered }\end{array} \\ \text { X Contraindicated }\end{array}$

\subsubsection{Aminosalicylates (FDA B)}

Sulfasalazine is the medication with the longest track record available for $\mathrm{CD}$. It is safe during pregnancy and nursing ${ }^{183} 198199$ (grade B,C). Kernicterus has been postulated as a potential consequence because of binding of the drug to plasma proteins, but it creates no clinical problems ${ }^{200}$ [EL4, RG C]. Folate is important for neural tube development during pregnancy, and as sulfasalazine treatment interferes with absorption, folate supplementation (about $2 \mathrm{mg} /$ day) is recommended. 5-ASA has also proved safe during pregnancy ${ }^{183}{ }^{201-204}$ for doses up to $3 \mathrm{~g} /$ day, but the safety of higher doses is uncertain [EL4, RG C]. Epidemiological database research has identified an increased risk of stillbirth or preterm birth in CD treated with 5-ASA, but could not determine whether this risk was secondary to active disease or medication. ${ }^{205}$ [EL3b, RG B]

\subsubsection{Antibiotics (FDA B-C)}

Antibiotics may be used as first line therapy for perianal $\mathrm{CD},{ }^{206}$ most often metronidazole and ciprofloxacin. Although metronidazole is mutagenic in some bacteria and carcinogenic in mice after long term use, this has never been reported in humans ${ }^{207}$ [ELla, RG A]. Metronidazole is considered safe by most obstetricians after the first trimester. $^{172}$ [EL5, RG D] Two studies on fluoroquinolones, in which the majority of patients had treatment in the first trimester, failed to show any increased risk of malformation, spontaneous abortion, prematurity, or low birth weight. ${ }^{208} 209$ [EL3b, RG B]

Tetracyclines and sulphonamides should be avoided during pregnancy. Tetracyclines can cause retardation of fetal skeletal development. Sulphonamides interfere with folic acid metabolism and are teratogenic in animals, which develop cleft palate and have high mortality. ${ }^{210}[$ EL4, RG C]

\section{1.7.3 Corticosteroids (FDA C)}

Corticosteroids cross the placental barrier but are rapidly converted to less active metabolites by placental 11-hydroxygenase, resulting in low fetal blood concentrations. Prednisone and prednisolone are more rapidly metabolised than alternative compounds. Nevertheless, risks of prematurity, spontaneous abortion, or cleft palate ${ }^{211}$ [EL4, RG C] are often cited, which have only been seen in animals. In humans no increase in congenital malformations has been found. ${ }^{183} 212$ [EL3b, RG B] Enemas and suppositories are considered acceptable until the third trimester. ${ }^{213}$ [EL5, RG D]

\subsubsection{Budesonide (FDA C)}

No studies are available in humans with IBD, although studies with inhaled budesonide suggest that the drug is safe during pregnancy. ${ }^{214} 215$ [EL3b, RG B] In animals, toxic doses of budesonide have shwon both teratogenic and embryocidal effects. ${ }^{216}$ [EL4, RG C]

\subsubsection{AZA and 6-MP (FDA D)}

Most of the experience on AZA and 6-MP in pregnancy comes from the transplant and rheumatology literature. AZA is considered safe in these populations, with no consistent reports of abnormalities in fertility, prematurity, or congenital defects. ${ }^{217-219}$ [EL3b, RG B] The FDA rating is, however, based on human reports of high abortion rates. ${ }^{220} 221$ [EL4, RG C] Studies on animals given doses equivalent to $1.5 \mathrm{mg} / \mathrm{kg}$ for $6-\mathrm{MP}$ and $2.5 \mathrm{mg} / \mathrm{kg}$ for AZA, report only low birth weights, but higher doses have been associated with increased incidences of congenital malformations, prematurity, low birth weight, and chromosomal abnormalities. ${ }^{222} 223$ [EL3b, RG B] In IBD there have been follow up studies on 341 pregnancies during treatment with AZA or 6-MP. All resulted in normal deliveries and no excess rates of prematurity, spontaneous abortion, congenital abnormalities, or neonatal/childhood infections. ${ }^{224} 225$ [EL3b, RG B] The only prospective randomised study confirms that outcome in pregnant patients treated with thiopurines is similar to the general population. ${ }^{226}$ When fathers used 6-MP within three months of conception a study of 50 pregnancies reported a higher incidence of pregnancy related complications. ${ }^{227}$ [EL3b, RG B]Consequently, although AZA and 6-MP have FDA rating $\mathrm{D}$, available data suggest that these drugs are safe and well tolerated during pregnancy.

\section{1.7.6 CsA (FDA C)}

As for other immunosuppressants, most data in pregnancy come from transplant and rheumatology literature. ${ }^{217}$ 228-230 [EL4, la,3b, RG C,A,B] There is a higher rate of prematurity and low birth weight, but a high survival rate. Cyclosporin was used in two UC pregnancies without influence on fetal outcome. ${ }^{231}$ [EL4, RG C] There are no data available on the use of cyclosporin in pregnant CD patients; but the drug seems to be safe if clinically indicated.

\subsubsection{Tacrolimus (FDA C)}

The transplant literature reports apparent safety. ${ }^{232}$ [EL3b, RG B] Prematurity is more common, but no excess congenital malformations, low birth weight, or neonatal complications have been found.

\section{1.7.8 Methotrexate (FDA X)}

Animal studies have shown methotrexate to be both teratogenic and embryotoxic, resulting in chromosomal damage and miscarriage. ${ }^{217} 218$ [EL4, RG C] Although normal pregnancies have occurred, MTX is contraindicated in pregnancy. ${ }^{218} 233$ [EL4,3b, RG C,B] If conception should accidentally occur, therapeutic abortion should be discussed, but not necessarily performed. ${ }^{234}$ [EL5, RG D] Prospective mothers should be instructed to stop methotrexate immediately and start high dose folate replacement. ${ }^{234}$ [EL5, RG D]

Table 11.2 Prescribing in pregnancy

\begin{tabular}{lll}
\hline Considered safe & Probably safe & Contraindicated \\
\hline 5-ASA (FDA B) & Budesonide (FDA C) & Methotrexate (FDA X) \\
Antibiotics (FDA B) & Thiopurines (FDA D) & Thalidomide (FDA X) \\
Anti-TNF $\alpha$ (FDA B) & Quinolones (FDA C) & Sulphonamides (FDA C) \\
Corticoteroids (no rating) & Ciclosporin (FDA C) & Tetracycline (FDA D) \\
& Tacrolimus (FDA C) & \\
\hline
\end{tabular}


Table 11.3 Prescribing during breast feeding

\begin{tabular}{lll}
\hline Considered safe & Probably safe & Contraindicated \\
\hline Sulfasalazine & Budesonide & Methotrexate \\
Topical or oral mesalazine & Thiopurines & Thalidomide \\
Corticosteroids & Infliximab & Cyclosporin \\
& Olsalazine & Diphenoxylate \\
& Ciprofloxacin \\
& Metronidazole \\
& Loperamide \\
\hline
\end{tabular}

The intracellular metabolites of MTX, methotrexate polyglutamates, have a long half life and take about six weeks to reach steady state or to completely wash out. Thus, women should stop MTX for at least six weeks and probably longer. The same applies to prospective fathers, to allow spermatogenesis return to normal. [EL5, RG D]

\subsubsection{Infliximab (FDA B)}

Anti-TNF $\alpha$ antibodies are species specific. Murine models have failed to show any teratogenicity or embryotoxicity. Post-marketing data from Centocor of more than 280 pregnancies, of which a third had IFX during the first trimester showed that $75 \%$ had live births, $14 \%$ had a miscarriage, and $11 \%$ had therapeutic terminations ([EL4, RG C], personal communication, Troels Sørensen, Centocor). There is, however placental transfer of infliximab (high serum concentrations have been detected in the baby of a mother who received IFX $10 \mathrm{mg} / \mathrm{kg}$ every eight weeks during pregnancy), although it is not yet known whether this induced antibody formation in the baby ${ }^{235}$ IFX could not be detected in breast milk (below). The implications of exposure to IFX on the newborn are unknown, but patients and physicians should be aware of in utero exposure and treatment may best be avoided in the last trimester of pregnancy if circulating IFX in the neonate is to be avoided [EL5, RGD].

\section{1.7.10 Thalidomide (FDA X)}

Thalidomide is contraindicated in pregnancy. Use of this agent has been associated with major human fetal abnormalities involving not only limbs (phocomelia), but also ears and eyes. Neural tube abnormalities, duodenal fistulas, and haemangioma have been reported ${ }^{236}$ [EL4, RG C]. Neonatal mortality rates of $40 \%$ have been reported..$^{237}$ [EL4, RG C]

\subsubsection{Non-specific symptomatic agents}

Antiemetic (FDA B)

Metoclopramide is safe and no fetal abnormalities have been reported. $^{238}$ [EL4, RG C] Vitamin B6 used as antiemetic decreased nausea during pregnancy without teratogenic effect. $^{239}$ [EL2b, RG B] Ondansetron has also been reported to be safe ${ }^{240}[\mathrm{EL} 3 \mathrm{~b}, \mathrm{RG} \mathrm{B}]$.

Antacids and proton pump inhibitors (PPI) (FDA B, C) Antacids are safe during pregnancy, as is sucralfate. $\mathrm{H}_{2}$ receptor antagonists (FDA B) are considered safe. ${ }^{241}$ [EL2b, RG B] Omeprazole is in FDA category C, because although PPIs have not been found teratogenic in humans, they have in animal studies. ${ }^{242}$ [EL3b, RG B]

Pain relief (FDA C, D)

Aspirin (FDA D) has shown to cause prolonged gestations, prematurity, longer labour, and greater blood loss during labour and delivery. ${ }^{243}$ [EL4, RG C] NSAIDS (FDA C) have not been studied adequately and are not recommended. Codeine (FDA C) is considered safe. ${ }^{244}$ [EL5, RG D]
Antidiarrhoeals (FDA B)

Cholestyramine (FDA B) has anion binding capacity and is effective in controlling diarrhoea especially in patients with ileal disease or after resection and in those with cholestasis of pregnancy. Loperamide (FDA B) should be considered probably safe, although reports of congenital malformations have been reported in a selected group of patients. ${ }^{245}$ [EL4, RG C] Diphenoxylate should be used with caution.

\subsection{Medical treatment when breast feeding} (table 11.3)

Sulfasalazine is safe for breast feeding. The sulfapyridine moiety is absorbed in minimal amounts and is excreted in milk, however the milk:serum ratio is acceptable. ${ }^{200}$ [EL4, RG C] The safety of aminosalicylates has been confirmed in prospective trials. ${ }^{201} 202246$ [EL4,3b, RG C,B] Prednisone and prednisolone result in low human breast milk concentrations. To minimise exposure, a four hour delay after oral dosing could be recommended. ${ }^{217} 247248$ [EL3b,4, RG B,C] Very small amounts of AZA/6-MP metabolites (nanomolar concentrations of 6-methyl mercaptopurine and thiouric acid) appear in breast milk ${ }^{249}$ so their use should be discussed on an individual basis. There are no data to support the use of cyclosporin in breastfeeding. Infliximab could not be detected in milk in the one published case that it has been measured, although like other maternally acquired antibodies, the half life of infliximab appears prolonged in newborns after in utero exposure. ${ }^{235}$ The implications are unknown and breast feeding is probably best avoided while receiving infliximab. It is not known whether thalidomide is excreted in breast milk.

\subsection{AND PSYCHOSOMATICS}

\subsection{Introduction}

While psychosocial factors are considered important in CD, controversy still exists about their role. This may lead to inconsistencies in clinical practice. The biopsychosocial model $^{250}$ represents an advantage over the biomedical model, as it embodies the complex biological and psychosocial interactions that explain human illness or its effects. Attention to the psychosocial factors associated with CD may have consequences not only on psychosocial wellbeing and quality of life, but also on the activity of the disease itself.

\subsection{Psychosocial factors}

Patients with CD seem to have slightly higher frequencies (up to $50 \%$ ) of psychological disturbances and a lower quality of

\section{ECCO Statement 12A}

Psychological disturbances seem to be a consequence of the illness rather than the cause or specific to Crohn's disease. The degree of psychological distress correlates with the disease severity, predicts health related quality of life and influences the course of disease [EL1 b, $2 b$ and $3 b, R G B]$ 


\section{ECCO Statement 12B}

An association between psychological factors and the aetiology of Crohn's disease is unproven [EL3b, 4, RG D], but there is a moderate influence on the course of the disease [ELIb, 2b, RG B]

life compared to patients with ulcerative colitis (UC) or those with other chronic diseases. ${ }^{251-256}$ The psychosocial consequences of the illness become more significant with increasing severity of the disease..$^{255}$ 257-263 Studies about the influence of psychological factors on the development of $\mathrm{CD}$ are limited, ${ }^{254} 262$ but there is evidence that children and adolescents with IBD comprise a population at high risk of developing a psychiatric disorder. ${ }^{263}$ Psychological factors are considered to have a moderate influence on the course of the disease, which is consistent with evidence in the recent literature about the influence of psychological distress on $C D$ activity. ${ }^{264} 266$

\subsection{Psychological factors influencing the course of CD}

\section{ECCO Statement $12 \mathrm{C}$}

There is evidence of an interaction between psychological factors and IBD activity: Depression and perceived chronic distress seem to represent further risk factors for relapse of the disease. It remains unclear whether acute life events trigger relapses [EL1b,2b, RG B] Most patients consider stress to have an influence on their illness [EL2c,3, RG C]

Prospective studies suggest that patients with depressive mood and associated anxiety are at higher risk of further disease activity. ${ }^{263-266}$ For CD, in contrast with UC, prospective studies have yielded contradictory results about the influence of stress or (single) major life events on disease activity. ${ }^{262}$ 267-269 Patients themselves and most European experts at the consensus conference consider psychosocial distress as influencing the course of the disease. ${ }^{270} 271$

\subsection{Doctor-patient relationship, information, and clinical care}

\section{ECCO Statement 12D}

The psychosocial consequences and health related quality of life of patients should be taken into account in clinical practice at regular visits. Individual information and explanation about the disease should be provided through a personal interview. The course of the disease can be improved by combining self management and patient centred consultations [ELIb,3b, RG B]

Health perceptions impact on the experience of the illness. ${ }^{255}$ Increased physician awareness of the fact that psychologically distressed patients have difficulty in processing clinically relevant information ${ }^{272}$ may lead to improved doctorpatient communication. ${ }^{273}$ It is important to inform patients about their condition through an individual interview in conjunction with emotional support. ${ }^{274}$ This is because a lower information level is associated with greater concern. ${ }^{275}$ Self management guidebooks and patient centred consultations improve patients' disease control, ${ }^{276} 277$ but the addition of educational booklets on their own does not seem to be helpful and may even worsen the health related quality of life of patients attending tertiary centres. ${ }^{278}$ Patient education programmes seem to have very limited or even no influence on the course of the illness or the psychological affect of patients. ${ }^{279} 280$ Almost all experts at the consensus conference are convinced that a good doctor-patient relationship is helpful psychologically and take psychosocial factors into account in diagnosis and therapy. ${ }^{281}$ Most experts at tertiary centres have the opportunity for an integrative somatic and psychological care of patients in their area of work.

\subsection{Assessment of health related quality of life, psychological distress, and provision of integrated psychological support}

\section{ECCO Statement 12E}

Physicians should assess the patient's psychosocial status and demand for additional psychological care and recommend psychotherapy if indicated. Integrated psychosomatic care should be provided in IBD centres [EL2b, RG B]

\section{ECCO Statement $12 \mathrm{~F}$}

Patients should be informed of the existence of patient associations [EL 5, RG D]

For assessment of quality of life, two IBD specific questionnaires have been shown to have sensitive reliability, responsiveness, and validity for use in clinical trials: the inflammatory bowel disease questionnaire (IBDQ) ${ }^{282} 283$ and the rating form of inflammatory bowel disease patient concerns (RFIPC). ${ }^{255} 284$ Detection and treatment of psychological distress has the potential to improve health related quality of life. ${ }^{252}$

To assess the demand for psychological care in chronic diseases, a validated questionnaire is now available, developed and based on IBD. ${ }^{285}$ Most experts feel themselves able to recommend psychotherapy in a discussion with the patients. There is no study on this competence, although this clinical experience is consistent with that of the participants of the Consensus Conference of the German Society of Digestive and Metabolic Diseases on diagnosis and therapy of $\mathrm{CD}^{286}$ as well as that of UC. ${ }^{287}$ As strategies aimed at improving social support can have a favourable impact on psychological distress, ${ }^{288}$ training of gastroenterologists to integrate psychosocial factors in clinical practice should be taken into consideration.

\subsection{Psychotherapeutic interventions}

12.6.1 Psychotherapy

Psychotherapy has a positive effect mainly on the psychological dimensions of the illness such as psychological wellbeing, coping strategies, and psychological distress. ${ }^{289-291}$ The

\section{ECCO Statement $12 \mathrm{G}$}

Psychotherapeutic interventions are indicated for psychological disorders, such as depression, anxiety, reduced quality of life with psychological distress, as well as maladaptive coping with the illness [EL1b,2b,3b, RG B] 
diagnosis of "CD" alone is not sufficient to recommend psychotherapy. Studies of psychotherapy on patients without psychological disturbance show little or no benefit. ${ }^{292-295}$ One study combining patients with CD and UC has shown an influence of psychotherapy on the disease activity. ${ }^{291}$ However, this study shows inhomogeneity in randomisation of the treatment and control groups, so the results are not included in the evidence based recommendation.

\subsubsection{Choice of psychotherapeutic methods and psycho-pharmaceuticals}

\section{ECCO Statement $12 \mathrm{H}$}

The choice of psychotherapeutic method depends on the psychological disturbance and should best be made by specialists (psychotherapist, specialist for psychosomatic medicine, psychiatrist). Psycho-pharmaceuticals should be prescribed for defined indications [EL5, RG D]

There is no evidence that preference should be given to one psychotherapeutic method in particular. Relaxation exercises are useful, as they are easy to learn and perform on the one hand, and because of their proved effectiveness on the other. ${ }^{290} 291294$ There is an advantage if the psychotherapist has experience in the treatment of patients with chronic IBD and works closely with the patient's gastroenterologist.

There are also no specific studies for the use of individual psycho-pharmaceuticals in CD. Despite this, most experts believe there are clinical situations in which psychopharmaceuticals should be recommended for treatment of psychological distress associated with $\mathrm{CD}$, rather than disease activity.

\subsection{EXTRAINTESTINAL MANIFESTATIONS OF CD \\ 13.1 Introduction}

Extraintestinal manifestations (EIMs) are comparatively common in CD, and reports show that up to $30 \%$ of patients are affected. ${ }^{296-298}$ However EIMs are likely to be overrepresented in studies from tertiary referral centres and community studies suggest that their prevalence may be much lower.

The occurrence of one EIM seems to predispose to others. Some EIMs are related temporally to CD activity, while others more usually run an independent course, unrelated to disease activity. Some forms of peripheral arthritis, erythema nodosum, oral aphthous ulcers, and episcleritis belong in the former group, while pyoderma gangrenosum uveitis, spondylarthropathy and primary sclerosing cholangitis (PSC) are characteristic of the latter. Joint manifestations in CD may be peripheral, axial, or both. Most gastroenterologists will be comfortable diagnosing and treating extraintestinal manifestations, with the exception of eye involvement for which the advice of an ophthalmologist is selected in a great majority of cases.

For those EIMs closely related to CD activity, treatment can parallel that of the underlying disease. Treatment otherwise is mainly on a case by case basis as RCTs are lacking. Specific therapy for EIMs is strongly influenced by current IBD treatment, and may include increasing dose of existing drugs or the addition of new agents. This contribution concentrates on the more frequently encountered EIMs, for which at least some quantifiable data exist, and does not include systemic consequences of severe CD such as iron deficiency or malnutrition.

\subsection{Articular manifestations}

\section{ECCO Statement 13A}

Diagnosis of non-axial arthritis and arthropathy associated with IBD is made on clinical grounds based on characteristic features and exclusion of other specific forms of arthritis [EL3b, RG C]. Type I is pauci-articular and affects large joints acutely at times of IBD activity, while type II is polyarticular, affecting a larger number of peripheral joints independently of IBD activity [EL 2b, RG B]. Axial arthritis, including sacroiliitis and ankylosing spondylitis, is diagnosed on conventional rheumatological grounds, and is supported by characteristic radiological changes, magnetic resonance imaging being the most sensitive [EL2b, RG B]. Although HLA B-27 is overrepresented in axial arthritis related to Crohn's disease and without diagnostic value [EL2b, RG B]

\subsubsection{Peripheral arthropathy}

Peripheral arthritis is now sub-classified to types I and II. ${ }^{299}$ Type I is pauci-articular and affects large (predominantly weight bearing) joints including the ankles, knees, hips, wrists, elbows, and shoulders. By convention fewer than five joints are affected. The arthritis is usually acute and self limiting (weeks rather then months) and leaves no permanent joint damage. Type II is a polyarticular arthritis mainly affecting the small joints of the hand; it persists longer (months or years) and may recur independently of CD activity. The diagnosis of peripheral arthritis is made clinically from the finding of painful swollen joints. The differential diagnosis includes osteoarthritis, septic arthritis, or coincidental sero-positive rheumatoid arthritis, or treatment side effects (which may include the effects of corticosteroid withdrawal, osteonecrosis, AZA induced arthropathy and infliximab related lupus-like syndrome. ${ }^{300}$

\subsubsection{Axial arthritis}

Axial arthritis includes spondylitis and sacroiliitis. ${ }^{300}$ Asymptomatic sacroiliitis is common, with up to $50 \%$ of Crohn's patients having abnormal radiography. Symptomatic sacroiliitis is characterised by pain in the buttocks after rest, which improves with movement. The leading symptom of ankylosing spondylitis is chronic low back pain, usually of onset before the age of 30 . The diagnosis is made clinically by physical examination showing limited spinal flexion and, in the later stages, reduced chest expansion. Conventional radiographs are often normal in the early stages of disease. While computed tomography and technetium bone scans are more sensitive than simple radiographs, the current gold standard is now magnetic resonance imaging. ${ }^{301} 302$ In more advanced cases there may be squaring of the vertebral bodies, marginal syndesmophytes, and bony proliferation, with ankylosis producing the classical "bamboo spine". HLA B27 associations are found in $50 \%-75 \%$ of patients with axial arthritis but HLA typing has no role in the management of an individual patient. ${ }^{303} 304$

In type I peripheral arthritis the emphasis should be on the treatment of the underlying $\mathrm{CD}$, including corticosteroids, immunomodulation, and anti-TNF agents as appropriate; this may be expected to result in improvement of joint symptoms. The joint specific drug of first choice for all forms of IBD related arthritis seems to be sulfasalazine, but reliable evidence to support this choice is lacking. Symptomatic relief may be obtained from simple analgesics, rest and physiotherapy. ${ }^{300} 305306$ Although there is concern that nonsteroidal anti-inflammatory agents (conventional and COX II 


\section{ECCO Statement 13B}

Treatment of arthritis and arthropathy associated with IBD is based almost entirely on extrapolation from that for other forms of arthritis. There is some general support for use of sulfasalazine, simple analgesics, non-steroidal anti-inflammatory agents, local corticosteroid injections, and physiotherapy, [EL4, RG D]. In the case of type I peripheral arthritis the emphasis should be on that of the underlying Crohn's disease [EL2c, RG C]. In axial arthritis the arguments in favour of intensive physiotherapy [EL2a, RG B], sulfasalazine [EL2a, RG C], methotrexate [EL3b, RG C], or infliximab [EL2a, RG C], are somewhat stronger

inhibitors) may aggravate the underlying $C D,{ }^{307-309}$ they have been used by many gastroenterologists to apparently good effect. Injection of corticosteroid into the worst affected joints may also be useful.

Treatment of axial arthritis in $\mathrm{CD}$ is based on a comparatively good evidence base for axial arthritis in general. It should therefore include intensive physiotherapy, together with rheumatological disease modifying drugs such as sulfasalazine, and methotrexate..$^{300} 306310$ The safety and efficacy of infliximab in ankylosing spondylitis is now established, but is not routinely used as a first line treatment. ${ }^{311}{ }^{312}$ The use of corticosteroids is poorly reported, but intra-articular injections can be appropriate in selected cases.

\subsection{Metabolic bone disease}

\section{ECCO Statement $13 \mathrm{C}$}

Diagnosis of osteoporosis is best made from a T score of less than -2.5 on radiographic bone densitometry [EL la, RG A], all other diagnostic methods having current limitations [EL2b, RG B]. The presence of osteoporosis identifies patients at above average risk for fracture and who should receive treatment [EL2b, RG B]. Osteopenia may be a prognostic marker for future osteoporosis, but presents little direct risk [EL2b, RG C]

Osteoporosis and osteopenia are common in both male and female patients with CD $(20 \%-50 \%){ }^{313}$ Contributing factors include age, corticosteroid treatment, smoking, low physical activity (including that from hospitalisation), inflammatory cytokines, extensive small bowel disease or resection, and nutritional deficiencies. Screening is appropriate in all patients with Crohn's in whom there has been evidence of severe disease and in those repeatedly exposed to corticosteroids. ${ }^{314}$ Diagnosis is conventionally based on bone densitometry (DEXA scanning), osteoporosis being defined from a T score of less than -2.5 . Ultrasound has been suggested as method of screening but is not yet reliable. The presence of osteoporosis increases the risk of fracture of long bones and of the spine, although probably a great deal less in young patients than was once thought. It is conventional to take a diagnosis of osteoporosis as an indication for specific therapy.

Osteopenia ( $\mathrm{T}$ score $<-1.0$ ) is thought by some to be an important risk factor for fracture in its own right, but this is increasingly questioned. ${ }^{314}$ It is probable that it is a marker of increased risk of later osteoporosis. Therapeutic intervention is probably not justified on present knowledge, but continued surveillance for bone loss is appropriate.

\section{ECCO Statement 13D}

Data on the treatment of osteoporosis in Crohn's disease depend on studies that are not specific to IBD. The evidence levels and recommendation grades are accordingly marked down. Weight bearing, isotonic exercise [EL2b, RG B], stopping smoking [EL3b, RG C], avoiding alcohol excess [EL4, RG D], and maintaining adequate dietary calcium (>1 g/day) [EL2b, RG B] are beneficial. Hormone replacement treatment is no longer generally advised in postmenopausal women with osteoporosis [EL2b, RG B], but regular use of bisphosphonates, calcitonin and its derivatives, and raloxifene may reduce or prevent further bone loss [EL2b, RG C]. Data in men with osteoporosis are less secure but bisphosphonates are probably of value, [EL3b, RG C], and those with low testosterone may benefit from its therapeutic administration [EL3b, RG C]. Routine administration of vitamin $D$ is not warranted [EL3b, RG C]

The risks of osteoporosis (and the potential risks from osteopenia) should be explained. General advice should include recommendations on exercise (particularly when weight bearing and isotonic), the cessation of smoking, and avoidance of alcohol excess. ${ }^{313}$ Evidence exists to recommend a dietary calcium intake of 1000-1500 mg per day. Postmenopausal women with osteoporosis have been offered treatment with hormone replacement therapy, but recent studies showing that this invokes an increased risk of breast cancer and of cardiovascular event ${ }^{315}$ have lead to a substantial restriction in its use. Data also exist to warrant treatment with bisphosphonates, calcitonin and its derivatives, and raloxifene. ${ }^{316}$ One of these should be selected for osteoporotic women with Crohn's. Men over the age of 50 with osteoporosis also deserve treatment, ${ }^{317}$ and seem to benefit from testosterone if their serum levels are low. Osteomalacia is also seen in CD but is comparatively rare in the absence of other risk factors. Routine administration of vitamin $\mathrm{D}$ is not warranted. ${ }^{316}$

\subsection{Cutaneous manifestations}

\section{ECCO Statement 13E}

Diagnosis of the cutaneous manifestations of IBD is made on clinical grounds, based on their characteristic features and (to some extent) the exclusion of other specific skin disorders; biopsy is rarely appropriate or necessary [EL3b, RG C]

The diagnosis of erythema nodosum is made from its characteristic raised, tender, red or violet subcutaneous nodules of $1 \mathrm{~cm}$ to $5 \mathrm{~cm}$ in diameter. It commonly affects the extensor surfaces of the extremities, particularly the anterior tibial area, and usually occurs at times of activity of the CD. A firm clinical diagnosis can normally be made, and biopsy is not normally appropriate. If performed, the histology reveals a non-specific focal panniculitis. ${ }^{318}$ The differential diagnosis of erythema nodosum includes metastatic CD, in which ulcerating nodules may appear at any site and the histology of which includes non-caseating granulomas.

Pyoderma gangrenosum lesions are often preceded by trauma at the same site (which may have been many years earlier) in a phenomenon known as pathergy. They can occur anywhere on the body, including the genitalia, but the 
commonest sites are on the shins and adjacent to stomas. Initially they take the form of single or multiple erythematous papules or pustules, but subsequent necrosis of the dermis leads to the development of deep excavating ulcerations that contain purulent material that is sterile on culture unless secondary infection has occurred.

\section{ECCO Statement 13F}

Treatment of erythema nodosum is usually based on that of the underlying Crohn's disease. Systemic corticosteroids are usually required [EL4, RG D]. Treatment of pyoderma gangrenosum has relied on topical and systemic corticosteroids [EL4, RG D], with the more toxic ciclosporin and tacrolimus reserved for resistant cases [EL4, RG D]. Newer data support the use of infliximab [EL1b, RG B]

The treatment of erythema nodosum will be mainly directed toward the underlying disease. ${ }^{318}$ Usually systemic corticosteroids will be required. In resistant cases and when there are frequent relapses immunomodulation with AZA and/or infliximab may be added, but it is most unusual to need such measures purely because of the erythema nodosum.

Corticosteroids have been considered the most effective treatment for pyoderma gangrenosum, ${ }^{319}$ and in resistant cases high intravenous doses have been thought required. Intravenous cyclosporin ${ }^{320}$ or tacrolimus ${ }^{321}$ are considered effective in refractory cases, but there are no reliable trials to support their use, and these drugs have significant side effects. Infliximab, reported to be effective in small case studies, ${ }^{322}$ has now shown its value in a small placebo controlled trial. ${ }^{323}$ The side effect profile and efficacy of IFX compared with high doses of corticosteroids, cyclosporin or tacrolimus are such that many now consider it the preferred treatment for established pyoderma gangrenosum.

\subsection{Ocular manifestations}

\section{ECCO Statement 136}

Diagnosis of simple episcleritis depends on the exclusion of the more sinister features of uveitis. When this is not possible referral to an ophthalmologist for expert opinion and slit lamp examination is wise [EL4, RG D]. Episcleritis may not require specific treatment, but will usually respond to topical corticosteroids [EL4, RG D]. Uveitis is treated with corticosteroids, and it may be necessary to use both topical and systemic routes [EL3b, RG C]. Immunomodulatory therapy has been thought helpful in resistant cases [EL4, RG D]

Uveitis and episcleritis are the most common manifestations of IBD. Episcleritis may be painless, presenting simply with hyperaemic sclera and conjunctiva, but itching and burning sensations may also occur. ${ }^{324}$ Uveitis is less common but has potentially more severe consequences. When related to CD it is frequently bilateral, insidious in onset, and long lasting. ${ }^{324}$ Patients complain of eye pain, blurred vision, photophobia, and headaches. The possibility of progression to loss of vision should prompt urgent referral to an ophthalmologist. Slit lamp examination will confirm the diagnosis and permit the differentiation between anterior and posterior uveitis.
Episcleritis may be self limiting but will usually respond to topical corticosteroids, simple analgesics alongside the treatment of the underlying CD. ${ }^{324}$

Uveitis prompts urgent ophthalmological referral and treatment as vision loss may occur. The treatment will usually consist of both topical and systemic corticosteroids. ${ }^{324}$ AZA, methotrexate, and infliximab have each been reported to be valuable in resistant cases.

\subsection{Hepatobiliary disease}

\section{ECCO Statement $13 \mathrm{H}$}

Diagnosis of hepatobiliary disorders in association with Crohn's disease follows the standard investigatory pathways prompted by abnormal liver function tests, with ultrasound scanning, and serology to identify specific auto-immune and infective causes [EL2a, RG B]. Magnetic resonance cholangiography is now established as the first line diagnostic test for primary sclerosing cholangitis [EL2a, RG B]. Primary sclerosing cholangitis substantially increases the risk of both cholangiocarcinoma and colorectal carcinoma [ELla, RG A]

Hepatobiliary disease is not unusual in CD. PSC is less common than in UC but constitutes the most important condition relatively specific to the underlying IBD. Pericholangitis, steatosis, chronic hepatitis, cirrhosis, and gallstone formation are also over-represented however, and many of the drugs used for Crohn's have the potential to cause hepatotoxicity. In most cases attention will be drawn to the condition by the finding of abnormal liver function tests rather than symptoms or signs of liver disease. A predominantly obstructive pattern of liver enzymes or the presence of biliary symptoms will prompt ultrasonographic assessment, which may show gallstone disease, steatosis, or frank cirrhosis; less often it will show an abnormal duct pattern suggestive of PSC. If ultrasound scanning is normal, drug side effects have been thought unlikely, and serological tests for other primary liver disease are negative then the probability of PSC is significantly increased. The usual diagnostic test now is magnetic resonance cholangiography (MRCP), which will show the characteristic pattern of irregular bile ducts, bearing zones of both narrowing and dilatation. ${ }^{325}{ }^{326}$ If MRCP is normal it is safer and probably more effective (given probable predominant small duct disease) to perform a liver biopsy than diagnostic endoscopic retrograde cholangiography (ERCP) to confirm a suspected diagnosis. ${ }^{326}{ }^{327}$ PSC is a major risk factor for cholangiocarcinoma and colon cancer. ${ }^{327}$

\section{ECCO Statement 13I}

PSC seems to respond to ursodeoxycholic acid (ursodiol), which improves abnormal liver function tests [EL1b, RG B] may, at $20 \mathrm{mg} / \mathrm{kg}$, improve prognosis [EL2a, RG C], and will perhaps reduce the risk of colonic cancer in these patients [EL2a, RG C]. ERCP may be used to treat dominant strictures by dilatation and/or stenting [EL4, RG C]. Advanced liver disease may necessitate transplantation [EL2a, RG B]

Ursodeoxycholic acid (ursodiol), was promptly adopted as a treatment for PSC once it was shown reproducibly to improve liver enzymes, ${ }^{328}$ but it has taken some time for 
reasonably convincing evidence to emerge supporting true benefit from a $20 \mathrm{mg} / \mathrm{kg}$ daily dose in respect of histological progression. ${ }^{329}$ The addition of corticosteroids has been examined with conflicting results. Ursodiol may however reduce colon cancer risk. ${ }^{330}$ Tacrolimus has yielded a rapid decrease in liver enzymes but no histological improvement. ${ }^{331}$ ERCP may still be needed to confirm the diagnosis of PSC in a few cases, but it retains a place in the management of dominant biliary strictures. ${ }^{327}$ In advanced disease with liver failure there is no alternative to liver transplantation. ${ }^{327}$

\subsection{ALTERNATIVE THERAPIES FOR CD}

\section{1 Introduction}

The use of complementary and alternative medicine among IBD patients is common, ${ }^{332} 333$ and physicians are frequently confronted with questions about their use. However, evidence of efficacy and safety is often lacking, because there are only a few controlled trials that have assessed these therapies in IBD. As most of the reported studies contain methodological problems, it is often difficult for physicians to inform their patients adequately.

\subsection{Confounding factors}

Several factors can lead both doctors and patients to think that an alternative therapy has worked, when in fact it has not. This is as true for new treatments in scientific medicine as it is for fringe practices in "complementary or alternative medicine" (CAM). The only way to control for this is to conduct properly powered, RCTs. For IBD, confounding factors include:

- the natural history runs a cyclical course, so alternative therapies will have repeated opportunities to coincide with periods of remission that would have happened anyway

- placebo does work: through suggestion, belief, expectancy, cognitive reinterpretation, or diversion of attention, patients given biologically useless treatments often experience measurable relief. In recent IBD trials, placebo rates as high as $50 \%$ have been reported.

- if improvement occurs after IBD patients have had both "alternative" and science based treatment, the alternative strategy sometimes gets a disproportionate share of the credit from patients, IBD groups, or organisations with vested interests.

In general, complementary and alternative therapies remain largely unregulated, although adverse drug reactions to CAM have more than doubled over the past three years (World Health Organisation). It is for this reason that the WHO have recently published a new set of guidelines (http:// www.who.int/medicines/library/trm/Consumer.pdf) for national health authorities to develop context specific and reliable information for use of complementary and alternative medicines by consumers.

\subsection{Definitions}

\section{ECCO Statement 14A}

The definition of alternative therapy is one that is used in place of conventional medicine. Complementary therapies are similar treatments used alongside conventional medicine [EL5, RG D]

Complementary and alternative medicine is a group of diverse medical and health care systems, practices, and products that are not presently considered part of conventional medicine. While some evidence exists regarding some therapies, for most there are key questions that have yet to be answered through well designed scientific studies. Complementary and alternative therapies are different entities: complementary therapy is used together with conventional medicine, while alternative therapy is used in place of conventional medicine. Distinctions ought to be made between beneficial alternative therapies, strategies complementary to routine practice and health frauds.

\subsection{Use and prevalence}

\section{ECCO Statement 14B}

Physicians treating Crohn's disease patients should inquire about the use of both alternative and complementary treatments, because they are widely used and some have the potential for adverse effects [EL4, RG D]

An appreciable number of IBD patients use complementary therapies to manage their disease. A survey in 2003 among 150 IBD patients from a tertiary centre revealed that up to $60 \%$ of patients used CAM. ${ }^{334}$ No differences were detected with regard to disease diagnosis, education level, employment status, use of IBD medications, number of hospitalisations, doctor visits, or GI specific doctor visits. The most commonly used therapies were diet $(45 \%)$, herbal (17\%), exercise $(15 \%)$, prayer (11\%), and relaxation (10\%). Reasons for turning to CAM were abdominal pain/cramps (64\%), diarrhoea $(60 \%)$, and gas/bloating $(21 \%)$. This is in contrast with a national German study that found that the cumulative dose of corticosteroids was associated with use of CAM. ${ }^{333} \mathrm{~A}$ study in children and young adults found that $40 \%$ used CAM in addition to conventional therapies. ${ }^{335}$ The most common CAMs were megavitamin therapy (19\%), dietary supplements (17\%), and herbal medicine (14\%). As most patients using CAM attribute "significant" benefits to their CAM use, physicians should inquire about their use.

\subsection{Choice and evidence}

\section{ECCO Statement $14 C$}

There is insufficient evidence to recommend exclusive use of alternative therapies instead of conventional medicine in Crohn's disease*. However, the public interest in alternative and complementary treatments warrants further evaluation. [EL4, RG D]. *This includes the following treatments: acupuncture, aromatherapy, chiropractic, dietary supplements, electromagnetic fields, homoeopathic, massage, naturopathic, osteopathic, qi-gong, reiki, therapeutic touch, traditional Chinese medicine.

All alternative therapies for CD should be supported by scientific evidence of efficacy, so they should be evaluated using the same general approach about effectiveness and safety as conventional therapy. Otherwise the agents may be no better than placebo (which, it should be realised, is not the same as no therapy). Although measures of patient satisfaction are an important part of the evaluation process, they need to be accompanied by more objective measures of quality of life improvement. Furthermore, the lay literature is a very poor source of reliable information for patients. One area of particular concern is the use of unlicensed herbal remedies that may contain harmful substances. 
Only a few studies are reported where the outcome supports the use of CAM. Gerhardt et al ${ }^{336}$ reported the efficacy and safety of the Boswellia serrata extract H15 with 5ASA for the treatment of active CD. In this randomised, double blind, verum controlled, parallel group study, 102 patients were randomised to either $\mathrm{Hl} 5$ or 5-ASA. No significant differences were detected, and the authors conclude that H15 is not inferior to 5-ASA. Gupta et al ${ }^{337}$ studied the gum resin of Boswellia serrata for the treatment of UC. Twenty patients received a preparation of the gum resin of Boswellia serrata (900 mg daily divided in three doses for six weeks) and 10 patients were given sulfasalazine ( $3 \mathrm{~g}$ daily divided in three doses for six weeks) and served as controls. Although no validated scoring system was used and the study was small, the authors saw improvement in 18 of 20 patients treated with Boswellia gum resin compared with 6 of 10 given sulfasalazine. Aloe vera gel was evaluated in UC patients in a double blind, randomised, placebo controlled trial. ${ }^{338}$ Forty four patients with active UC were randomly given oral aloe vera gel or placebo, $100 \mathrm{ml}$ twice daily for four weeks, in a 2:1 ratio. The primary end point was clinical remission (simple clinical colitis activity index $\leqslant 2$ ), sigmoidoscopic remission (Baron score $\leqslant 1$ ) and histological remission (Saverymuttu score $\leqslant 1)$. Clinical remission, improvement, and response occurred in nine (30\%), 11 (37\%), and $14(47 \%)$, respectively, of 30 patients given aloe vera gel. This compared with one $(7 \%)(p=0.09$; OR $5.6(0.6$ to 49$))$, one $(7 \%)(p=0.06$; OR 7.5 ( 0.9 to 66$))$, and two ( $14 \%)(\mathrm{p}<0.05$; OR 5.3 ( 1.0 to 27$)$ ), respectively, of 14 patients given placebo. The simple clinical colitis activity index and histological scores decreased significantly during treatment with aloe vera $(\mathrm{p}=0.01$ and $p=0.03$, respectively), but not with placebo. Sigmoidoscopic scores and laboratory variables showed no significant differences between aloe vera and placebo. Adverse events were minor and similar in both groups of patients. The authors concluded that oral aloe vera gel taken for four weeks was safe and more effective than placebo. A prospective, randomised, controlled, single blind clinical trial of acupuncture for active $\mathrm{CD}$ has also been conducted. The CDAI declined significantly after treatment, but did not reach the 100 point threshold of benefit. ${ }^{339}$

\section{ECCO Statement 14D}

While physicians may permit use of complementary medicines, they should discourage use of those for which there is evidence for toxicity. It is plausible that dietary supplements could have a biological effect and there is some evidence for a number of specific supplements, which is strongest in the case of fish oil. [EL2a, RG C]

As malnutrition is prevalent both in active IBD as well as in quiescent disease, nutrition is an essential, complementary component of conventional medicine in CD. However, nutritional therapy does not qualify for primary therapy (that is, alternative therapy) in adults, in contrast with paediatric IBD (see chapter on treatment of active disease). Supplementation of fish oil preparations in CD has been reported beneficial in IBD patients. For maintaining remission, a double blind, placebo controlled study in 78 patients with CD evaluated the effects of a fish oil preparation. This demonstrated a significant reduction in relapse rate. ${ }^{340}$

\subsection{Conclusions}

A distinction should be drawn between alternative and complementary medicines. Their widespread use should be recognised. Some of these agents exert plausible biological effects and warrant further investigation.

\section{ACKNOWLEDGEMENTS}

Funding was provided by the Robert Bosch Foundation (Stuttgart, Germany) a non-profit and non-pharmaceutical organisation. Additional support ECCO comes through annual subscriptions from member countries. Support from industry includes Abbott Laboratories, Giuliani SA, Ferring Pharmaceuticals, Protein Design Labs, Centocor, Schering Plough, Dr Falk Pharma, Shire, ELAN, and Given Imaging. Grateful thanks to all contributors, as well as to Mrs Ulrike Firley and Mrs Helen Small for secretarial support.

\section{Authors' affiliations}

R Caprilli, University of Rome "La Sapienza" Department of Clinical Sciences, Rome, Italy

M A Gassull, Department of Gastroenterology and Hepatology, Hospital Universitari Germans Trias i Pujol, Badalona, Spain

J C Escher, Erasmus MC-Sophia Children's Hospital, University Medical Centre, Rotterdam, Netherlands

G Moser, Department of Internal Medicine IV, University Hospital of

Vienna, Vienna, Austria

P Munkholm, Herlev Hospital, University of Copenhagen, Herlev,

Denmark

A Forbes, University College Hospital, London, UK

D W Hommes, Academic Medical Centre, Department of

Gastroenterology and Hepatology, Amsterdam, Netherlands

H Lochs, Clinic of General, Visceral, Vascular and Thoracic Surgery,

Charite Campus Mitte, Humboldt-University of Berlin, Berlin, Germany

E Angelucci, University of Rome, GI Unit, Department of clinical science, La Sapienza, Policlinico Umberto I, Rome, Italy

A Cocco, Gastroenterology Unit, University of Rome La Sapienza, Rome, Italy

B Vucelic, University Hospital Rebro, Division of Gastroenterology and Hepatology, Zagreb

H Hildebrand, Department of Women and Child Health, Astrid Lindgren

Children's Hospital, Stockholm, Sweden

S Kolacek, University Children's Hospital Zagreb, Department of

Gastroenterology and Nutrition, Klaiceva, Croatia

L Riis, Herlev Hospital, University of Copenhagen, Herlev, Denmark

M Lukas, IVth Medical Department, Charles University Hospital, Prague, Czech Republic

$\mathbf{R}$ de Franchis, Instituto di Medicina Interna, Cattedra di

Gastroenterologia Policlinico, Milan, Italy

M Hamilton, Department of Gastroenterology, The Royal Free Hospital, London, UK

G Jantschek, Stadtkrankenhaus Neuwied, Federal Republic of Germany

P Michetti, Centre Hospitalier Universitaire Vaudois, Division of

Gastroenterology, Lausanne, Switzerland

C O'Morain, M M Anwar, Adelaide and Meath Hospital, Department of Gastroenterology, Dublin

J L Freitas, Department of Gastroenterology and Hepatology, Hospital

Garcia de Orta, Almada, Portugal

I A Mouzas, Gastroenterology Department, University Hospital,

Heraklion, Greece

F Baert, Heilig Hartziekenhuis, Roeselare, Belgium

R Mitchell, EFFCA, Bournemouth, Dorset UK

C J Hawkey, Wolfson Digestive Disease Centres, University Hospital Nottingham, UK

\section{APPENDIX}

Participants by country

Austria: Gasché C, Moser G, Reinisch W, Starlinger M, Tilg H.

Belgium: Baert F, D'Haens G, Geboes K, Vermeire S.

Croatia: Kolacek S, Vucelic B.

Czech Republic: Lukas $M$.

Denmark: Munkholm P, Riis L.

France: Bouhnik Y, Colombel J-F, Cortot A, Lemann M, Marteau P, Tiret E.

Germany: Hildebrand H, Jantschek G, Kroesen A, Lochs

H, Schölmerich J, Schreiber S, Stange EF.

Greece: Kitis G, Mouzas I. 
Hungary: Latakos $\mathrm{P}$

Ireland: $\mathrm{O}^{\prime}$ Morain $\mathrm{C}$, Anwar MM.

Israel: Chowers $\mathrm{Y}$.

Italy: Angelucci A, Biancone L, Cocco A, Cottone $\mathrm{M}$, Caprilli R, de Franchis R, Gionchetti P, Prantera C, Vecchi M, Villanaci V.

Lithuania: Barakauskiene A, Kupcinskas L.

Netherlands: Escher H, Hommes DW.

Portugal: Freitas J.

Slovakia: Kasak M.

Spain: Gassull M.

Sweden: Hildebrand $\mathrm{H}$, Oresland $\mathrm{T}$.

Switzerland: Beglinger C, Michetti P.

United Kingdom: Forbes A, Hamilton M, Hawkey CJ, von Herbay A, Mitchell R, Mortensen NM, Satsangi J, Travis SPL, Warren BF.

Working party members (chair underlined)

\section{Clinical diagnosis and imaging}

Walter Reinisch, Chris Beglinger, Limas Kupcinskas

\section{The histological diagnosis of Crohn's disease}

Karel Geboes, Ausrine Barakauskiene, Vincenzo Villanacci, Axel Von Herbay, Bryan Warren

\section{Classification of Crohn's disease}

Stefan Schreiber, Severine Vermeire, Herbert Tilg, Christoph Gasche, Jürgen Schölmerich

\section{Medical management of active Crohn's disease}

Simon Travis, Eduard Stange, Yehuda Chowers, Alastair Forbes, Geert D'Haens, George Kitis, Antoine Cortot, Cosimo Prantera, Philippe Marteau, Jean Frédéric Colombel

Management of medically induced remission Marc Lémann, Paolo Gionchetti, Yoram Bouhnik

\section{Surgery for Crohn's disease}

Tom Öresland, Neil Mortensen, Emmanuel Tiret, Anton Kroesen, Michael Starlinger

\section{Postoperative recurrence in Crohn's disease}

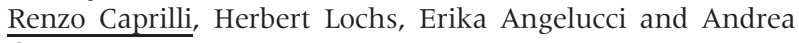
Cocco

\section{Diagnosis and management of fistulating Crohn's disease Miquel A. Gassull, Boris Vucelic, Michael Starlinger,}

\section{Crohn's disease in children and adolescents: diagnosis and treatment} Johanna C. Escher, Hans Hildebrand, Sanja Kolacek

\section{Pregnancy in Crohn's disease}

Pia Munkholm, Lene Riis, Milan Lukás, Roberto de Franchis, Marc Hamilton

\section{Crohn's disease and psychosomatics}

Gabrielle Moser, Günter Jantschek, Pierre Michetti

Extraintestinal manifestations of Crohn's disease Colm O'Morain, M M Anwar, Joao Freitas, Ianis Mouzas, Filip Baert, Alastair Forbes

\section{Alternative therapies for Crohn's disease Daan Hommes, Rod Mitchell, Chris Hawkey}

\section{REFERENCES FOR SECTION 3 (SPECIAL SITUATIONS)}

1 Rutgeerts P, Geboes K, Vantrappen G, et al. Predictability of the postoperative course of Crohn's disease. Gastroenterology 1990;99:956-63.

2 Caprilli R, Andreoli A, Capurso L, Gruppo Italiano per lo Studio del Colon e del Retto (GISC), et al. Oral mesalazine (5-aminosalicylic acid; Asacol) for the prevention of post-operative recurrence of CD. Aliment Pharmacol Ther 1994;8:35-43.

3 Rutgeerts P, Geboes K, Vantrappen G, et al. Natural history of recurrent Crohn's disease at the ileocolonic anastomosis after curative surgery. Gut 1984;25:665-72

4 Whelan G, Farmer RG, Fazio WW, Goormastic M. Recurrence after surgery in Crohn's disease. Gastroenterology 1985;88:1826-33.

5 Tytgat GNJ, Mulder CJJ, Brummelkamp WH. Endoscopic lesions in Crohn's disease early after ileocecal resection. Endoscopy 1988;20:260-2.

6 Olaison G, Smedh K, Sjodahl R. Natural course of Crohn's disease after ileocolic resection: endoscopically visualized ileal ulcers preceding the symptoms. Gut 1992;33:331-5

7 Michelassi F, Balestracci T, Chappell R, et al. Primary and recurrent Crohn's disease. Experience with 1379 patients. Ann Surg 1991;214:230-40.

8 Williams JG, Wong WD, Rothenberger DA, et al. Recurrence of Crohn's disease after resection. Br J Surg 1991;78:10-19.

9 Goldberg PA, Wright JP, Gerber M, et al. Incidence of surgical resection for Crohn's disease. Dis Colon Rectum 1993;36:736-9.

10 Borley NR, Mortensen NJ, Jewell DP. Preventing postoperative recurrence of Crohn's disease. Br J Surg 1997;84:1493-502.

11 Viscido A, Corrao G, Taddei G, et al. "Crohn's disease activity index" is inaccurate to detect the post-operative recurrence in Crohn's disease. A GISC study. Ital J Gastroenterol Hepatol 1999;31:274-9.

12 Cammà C, Giunta M, Rosselli $M$, et al. 5-aminosalicylic acid in the maintenance treatment of Crohn's disease: a meta-analysis adjusted for confounding variables. Gastroenterology 1997;113:1465-73.

13 Cottone M, Rosselli M, Orlando A, et al. Smoking habitus and recurrence in Crohn's disease. Gastroenterology 1994;106:643-8.

14 Breuer-Katschusky BD, Hollander N, et al. Effect of cigarette smoking on the course of Crohn's disease. Eur J Gastroenterol Hepatol 1996;8:225-8.

15 Sutherland LR, Ramcharan S, Bryant H, et al. Effect of cigarette smoking on recurrence of Crohn's disease. Gastroenterology 1990;98:1123-8.

16 Moskovitz D, McLeod RS, Greenberg GR, et al. Operative and environmental risk factors for recurrent Crohn's disease. Int J Colorectal Dis 1999;14:224-6.

17 D'Haens G, Gasparaitis AE, Hanauer SB. Duration of recurrent ileitis after ileocolonic resection correlates with preseurgical extent of Crohn's disease. Gut 1995;36:715-17

18 McLeod R, Wolff B, Steinhart HA. Risk and significance of endoscopic/ radiological evidence of recurrent Crohn's disesase. Gastroenterology 1997;113:1823-7.

19 Kotanagi H, Kramer K, Fazio V, et al. Do microscopic abnormalities at resection margins correlate with increased anastomotic recurrence in Crohn's disease? Dis Colon Rectum 1991;34:909-16.

20 Aeberhand $\mathbf{P}$, Berchtold W, Riedtmann HJ, et al. Surgical recurrence of perforating and non-perforating Crohn's disease. A study of 101 surgically treated patients. Dis Colon Rectum 1996;39:80-7.

21 Lock MR, Farmer RG, Fazio VW, et al. Recurrence and reoperation for Crohn's disease: the role of disease location in prognosis. N Engl J Med 1981;304:1586-8.

22 Hellborg R, Hulten $L$, Rosengren $C$, et al. The recurrence rate after primary excisional surgery for Crohn's disease. Acta Chir Scand 1980;146:435-43.

23 Lindhagen $T$, Ekelund $G$, Leandoer $L$, et al. Recurrence rate after surgical treatment of Crohn's disease. Scand J Gastroenterol 1983;18:1037-44.

24 Trnka YM, Glotzer DJ, Kasdon EJ, et al. The long-term outcome of restorative operation in Crohn's disease. Influence of location, prognostic factors and surgical guidelines. Ann Surg 1982;196:345-55

25 Shivananda S, Hordijk ML, Pena SA, et al. Crohn's disease: risk of recurrence and reoperation in a defined population. Gut 1989:30:990-8.

26 Ellis L, Calhoun P, Kaiser DL, et al. Post-operative recurrence in Crohn's disease. The effect of the initial length of bowel resection and operative procedure. Ann Surg 1984;199:340-7.

27 Bergman L, Krause U. Crohn's disease: a long-term study of the clinical course in 186 patients. Scand J Gastroenterol 1977;12:937-44.

28 Nygaard K, Fausa O. Crohn's disease. Recurrence after surgical treatment. Scand J Gastroenterol 1977; 12:577-84

29 Karesen R, Serch-Hanssen A, Thoresen BO, et al. Crohn's disease: long-term results of surgical treatment. Scand J Gastroenterol 1981;16:57-64.

30 Himal HS, Belliveau PB. Prognosis after surgical treatment for granulomatous enteritis and colitis. Am J Surg 1981;142:347-9.

31 Mekhjiam HS, Switz DM, Watts HD, et al. National cooperative Crohn's disease study: factors determining recurrence of Crohn's disease after surgery. Gastroenterology 1979;77:907-13.

32 Bernell O, Lapidus A, Hellers G. Risk factors for surgery and post-operative recurrence in Crohn's disease. Ann Surg 2000;210:38-45.

33 Atwell JD, Duthie HL, Goligher JC. The outcome of Crohn's disease. Br J Surg 1965:52:966-72

34 Soffley A, Myren J, Clamp SE, et al. Factors affecting recurrence after surgery for Crohn's disease. Scand J Gastroenterol Suppl 1988;144:S31-4.

35 Higgens CS, Allan RN. Crohn's disease of the distal ileum. Gut 1980;21:933-40.

36 Truelove SC, Pena AS. Course and prognosis of Crohn's disease. Gut 1976;17:192-201.

37 De Dombal FT, Burton I, Goligher JC. Recurrence of Crohn's disease after primary excisional surgery. Gut 1971;12:519-27.

38 Stahlgren LH, Ferguson LK. The results of surgical treatment of chronic regional enteritis. JAMA 1961;175:986-9.

39 Sachar DB, Wolfson DM, Greenstein AJ, et al. Risk factors for post-operative recurrence of Crohn's disease. Gastroenterology 1983;85:917-21.

40 Wolfson DM, Sachar DB, Cohen A, et al. Granulomas do not affect postoperative recurrence in Crohn's disease. Gastroenterology 1982;83:405-9. 
41 Fawaz KA Glotzer DJ, Goldman H, et al. Ulcerative colitis and Crohn's disease of the colon - a comparison of the long-term post-operative course. Gastroenterology 1976;71:372-8.

42 Homan WP, Gray GF, Dineen P. Granulomas in Crohn's disease. Lancet 1978;ii: 112.

43 Speranza V, Simi M, Leardi S, et al. Recurrence of Crohn's disease after resection. Are there any risk factors? J Clin Gastroenterol 1986;8:640-6.

44 Van Pattern EN, Bargen JA, Dockerty MB, et al. Regional enteritis. Gastroenterology 1954;26:347-450.

45 Cooke WT, Mallas E, Prior P, et al. Crohn's disease: course, treatment and long-term prognosis. Q J Med 1980;49:363-84. 46 Kyle J. Prognosis after ileal resection for Crohn's disease. Br J Surg
$1971 ; 58: 735-7$.

47 Lautenbach E, Berlin JA, Lichtenstein GR. Risk factors for early post-operative recurrence of Crohn's disease. Gastroenterology 1998;115:259-67.

48 Greenstein AJ, Lachman P, Sachar DB, et al. Perforating and nonperforating indications for repeated operations in Crohn's disease: evidence for two clinical forms. Gut 1988;29:588-92.

49 Sachar DB, Subrami K, Mauer K, et al. Patterns of post-operative recurrence in fistulizing and stenotic Crohn's disease. A retrospective cohort study of 71 patients. J Clin Gastroenterol 1996;22:114-16.

50 McDonald PJ, Fazio VW, Farmer RG, et al. Perforationg and nonperforating Crohn's disease. An unpredictable guide to recurrence after surgery. Dis Colon Rectum 1989;32:117-20.

51 Caprilli R, Corrao G, Taddei G, et al. Prognostic factors for post-operative recurrence of Crohn's disease. Dis Colon Rectum 1996;39:1-7.

52 Griffiths AM, Wesson DE, Shadling B, et al. Factors influencing postoperative recurrence of Crohn's disease in childhood. Gut 1991;32:491-5.

53 Caprilli R, Taddei G, Viscido A. In favour of prophylactic treatment for postoperative recurrence in Crohn's disease. Ital J Gastroenterol Hepatol 1998; 30:219-25.

54 Breslin NP, Sutherland LR. The case against routine post-operative therapy for prevention of recurrence in Crohn's disease. Ital J Gastroenterol Hepatol 1998;30:226-30.

55 McLeod RS, Wolff BG, Steinhart AH, et al. Prophylactic mesalamine treatment decreases postoperative recurrence of Crohn's disease. Gastroenterology 1995;109:404-13.

56 Brignola C, Cottone M, Pera A, et al. Mesalamine in the prevention of endoscopic recurrence after intestinal resection for Crohn's disease. Gastroenterology 1995;108:345-9.

57 Lochs H, Mayer M, Fleig WE, ECCDS, et al. Prophylaxis of post-operative relapse in Crohn's disease with mesalamine: European cooperative Crohn's disease study VI. Gastroenterology 2000;1 18:264-73.

58 Cottone M, Cammà C. Mesalamine and relapse prevention in Crohn's disease. Gastroenterology 2000;1 18:597.

59 Caprilli $R$, Cottone $M$, Tonelli $F$, et al. Two mesalazine regimens in the prevention of the post-operative recurrence of Crohn's disease: a pragmatic, double-blind, randomized controlled trial. Aliment Pharmacol Ther 2003; 17:517-23.

60 Cammà C, Viscido A, Latella G, et al. Mesalamine in the prevention of clinical and endoscopic post-operative recurrence of Crohn's disease: a meta-analysis. Dig Liver Dis 2002;34:A86)

61 Florent C, Cortot A, Quandale P, et al. Placebo-controlled clinical trial of mesalazine in the prevention of early endoscopic recurrences after resection for Crohn's disease. Eur J Gastroenterol Hepatol 1996;8:229-33.

62 Rutgeerts P, Hiele M, Geboes K, et al. Controlled trial of metronidazole treatment for prevention of Crohn's recurrence after ileal resection. Gastroenterology 1995;108:1617-21.

63 Rutgeerts P, Assche GV, Vermeire S, et al. Ornidazole for prophylaxis of post-operative Crohn's disease: a randomized, double blind, placebocontrolled trial. Gastroenterology 2005;128:856-61.

64 Hanquer SB, Korelitz BI, Rutgeerts P, et al. Post-operative maintenance of Crohn's disease remission with 6-mercaptopurine, mesalamine or placebo: a 2 year trial. Gastroenterology 2004;127:723-9.

65 Korelitz B, Hanauer S, Rutgeerts P, et al. Post-operative prophylaxis with 6MP, 5-ASA or placebo in Crohn's disease: a 2 year multicenter trial. Gastroenterology 1998;114:A1011.

66 Prantera C, Scribano ML, Falasco G, et al. Ineffectiveness of probiotics in preventing recurrence after curative resection for Crohn's disease: a randomised controlled trial with Lactobacillus GG. Gut 2002;51:405-9

67 Campieri M, Rizzello F, Venturi A, et al. Combination of antibiotic and probiotic treatment is efficacious in prophylaxis of post-operative recurrence in Crohn's disease: a randomized controlled study vs mesalamine. Gastroenterology 2000;118:A781.

68 Colombel JF, Rutgeerts P, Malchow H, et al. Interleukin 10 (Tenovil) in the prevention of post-operative recurrence of Crohn's disease. Gut 2001;49:42-6.

69 Viscido A, Corrao G, Taddei G, et al. Crohn's disease activity index is inaccurate to detect the post-operative recurrence in Crohn's disease. A GISC study. Ital J Gastroenterol Hepatol 1999;31:274-9.

70 Maccioni F, Viscido A, Marini M, et al. MRI evaluation of Crohn's disease of the small and large bowel with the use of negative superparamagnetic oral contrast agents. Abdom Imaging 2002;27:384-93.

71 Parente F, Greco S, Molteni M, et al. Modern imaging of Crohn's disease using bowel ultrasound. Inflamm Bowel Dis 2004;10:452-61.

72 D'Haens G, Geboes K, Ponette E, et al. Healing of severe recurrent ileitis with azathioprine therapy in patients with Crohn's disease. Gastroenterology 1997; 112:1475-81.

73 Cuillerier E, Lemann M, Bouhnik Y, et al. Azathioprine for prevention of postoperative recurrence in Crohn's disease: a retrospective study. Eur J Gastroenterol Hepatol 2001;13:1291-6.
74 Ardizzone S, Maconi G, Sampietro GM, et al. Azathioprine and mesalamine for prevention of relapse after conservative surgery for Crohn's disease. Gastroenterology 2004;127:730-7.

75 Keighley MR, Allan RN. Current status and influence of operation on perianal Crohn's disease. Int J Colorectal Dis 1986;1:104-7.

76 Hellers G, Bergstrand O, Ewerth S, et al. Occurrence and outcome after primary treatment of anal fistulae in Crohn's disease. Gut 1980;21:525-7.

77 Schwartz DA, Loftus EV, Tremaine WJ, et al. The natural history of fistulizing Crohn's disease in Olmsted County, Minnesota. Gastroenterology 2002; 122:875-80.

78 Haggett PJ, Moore NR, Shearman JD, et al. Pelvic and perineal complications of Crohn's disease: assessment using magnetic resonance imaging. Gut 1995:36:407-10.

79 Skalej M, Makowiec F, Weinlich M, et al. Magnetic resonance imaging in perianal Crohn's disease. Dtsch Med Wochenschr 1993;118:1791-6.

80 Koelbel G, Schmiedl U, Majer MC, et al. Diagnosis of fistulae and sinus tracts in patients with Crohn disease: value of MR imaging. Am J Roentgenol 1989; 152:999-1003.

81 van Bodegraven AA, Sloots CE, Felt-Bersma RJ, et al. Endosonographic evidence of persistence of Crohn's disease-associated fistulas after infliximab treatment, irrespective of clinical response. Dis Colon Rectum 2002; 45:39-46

82 Sloots CE, Felt-Bersma RJ, Poen AC, et al. Assessment and classification of fistula-in-ano in patients with Crohn's disease by hydrogen peroxide enhanced transanal ultrasound. Int J Colorectal Dis 2001;16:292-7.

83 Orsoni P, Barthet M, Portie F, et al. Prospective comparison of endosonography, magnetic resonance imaging and surgical findings in anorectal fistula and abscess complicating Crohn's disease. Br J Surg 1999;86:360-4.

84 Parks AG, Gordon PH, Hardcastle J. A classification of fistula-in-ano. Br J Surg 1976;63:1-12.

85 Bell SJ, Williams AB, Wiesel P, et al. The clinical course of fistulating Crohn's disease. Aliment Pharmacol Ther 2003;17:1145-51.

86 Sandborn WJ, Fazio VW, Feagan BG, et al. AGA technical review on perianal Crohn's disease. Gastroenterology 2003;125:1508-30.

87 Berstein LH, Frank MS, Brandt $\sqcup$, et al. Healing of perineal Crohn's disease with metronidazole. Gastroenterology 1980;79:357-65.

88 Brandt LJ, Berstein LH, Boley SJ, et al. Metronidazole therapy for perineal Crohn's disease: a follow-up study. Gastroenterology 1982;83:383-7.

89 Jakobovits J, Schuster MM. Metronidazole therapy for Crohn's disease and associated fistulae. Am J Gastroenterol 1984;79:533-40.

90 Solomon MJ, McLeod RS, O'Connor BI, et al. Combination ciprofloxacin and metronidazole in severe perianal Crohn's disease. Can J Gastroenterol 1993;7:571-3.

91 Pearson DC, May GR, Fick GH, et al. Azathioprine and 6-mercaptopurine in Crohn's disease. A meta-analysis. Ann Intern Med 1995;122:132-42.

92 Korelitz BI, Adler DJ, Mendelsohn RA, et al. Long-term experience with 6mercaptopurine in the treatment of Crohn's disease. Am J Gastroenterol 1993;88:1198-205.

93 Present $\mathrm{DH}$, Rutgeerts $\mathrm{P}$, Targan S, et al. Infliximab for the treatment of fistulas in patients with Crohn's disease. N Engl J Med 1999;340:1398-405.

94 Sands BE, Anderson FH, Bernstein CN, et al. Infliximab maintenance therapy for fistulizing Crohn's disease. N Engl J Med 2004;350:876-85.

95 Sands BE, Blank MA, Patel K, et al. Long-term treatment of rectovaginal fistulas in Crohn's disease: response to infliximab in the ACCENT II Study. Clin Gastroenterol Hepatol 2004;2:912-20.

96 Lichtenstein GR, Yan S, Bala M, et al. Infliximab maintenance treatment reduces hospitalizations, surgeries and procedures in fistulizing Crohn's disease. Gastroenterology 2005; 128:862-9.

97 Farrell RJ, Shah SA, Lodhavia PJ, et al. Clinical experience with infliximab therapy in 100 patients with Crohn's disease. Am J Gastroenterol 2000;95:3490-7

98 Ricart E, Panaccione R, Loftus EV, et al. Infliximab for Crohn's disease in clinical practice at the Mayo Clinic: the first 100 patients. Am J Gastroenterol $2001 ; 96: 722-9$

99 Sandborn WJ. A critical review of cyclosporine therapy in inflammatory bowel disease. Inflam Bowel Dis 1995;1:48-63.

100 Sandborn WJ. Preliminary report on the use of oral tacrolimus (FK506) in the treatment of complicated proximal small bowel and fistulizing Crohn's disease. Am J Gastroenterol 1997;92:876-9.

101 Fellermann K, Ludwig D, Stahl M, et al. Steroid-unresponsive acute attacks of inflammatory bowel disease: immunomodulation by tacrolimus (FK506). Am J Gastroenterol 1998;93:1860-6.

102 Lowry PW, Weaver AL, Tremaine WJ, et al. Combination therapy with oral tacrolimus (FK506) and azathioprine or 6-mercaptopurine for treatmentrefractory Crohn's disease perianal fistulae. Inflamm Bowel Dis 1999:5:239-45.

103 lerardi E, Principi M, Rendina M, et al. Oral tacrolimus (FK 506) in Crohn's disease complicated by fistulae of the perineum. J Clin Gastroenterol 2000:30:200-2.

104 Sandborn WJ, Present DH, Isaacs KL, et al. Tacrolimus for the treatment of fistulas in patients with Crohn's disease: a randomized, placebo-controlled trial. Gastroenterology 2003;125:380-8.

105 Baert F, Noman M, Vermeire S, et al. Influence of immunogenicity on the long-term efficacy of infliximab in Crohn's disease. N Engl J Med 2003:348:601-8.

106 Askling J, Grahnquist L, Ekbom A, et al. Incidence of paediatric Crohn's disease in Stockholm, Sweden. Lancet 1999;354:1179.

107 Armitage E, Drummond HE, Wilson DC, et al. Increasing incidence of both juvenile-onset Crohn's disease and ulcerative colitis in Scotland. Eur J Gastroenterol Hepatol 2001;13:1439-47. 
108 Urne FU, Paerregaard A. [Chronic inflammatory bowel disease in children. An epidemiological study from eastern Denmark 1998-2000]. Ugeskr Laeger 2002;164:5810-14.

109 Hildebrand H, Finkel Y, Grahnquist L, et al. Changing pattern of paediatric inflammatory bowel disease in northern Stockholm 1990-2001. Gut 2003;52:1432-4.

110 Phavichitr N, Cameron DJ, Catto-Smith AG. Increasing incidence of Crohn's disease in Victorian children. J Gastroenterol Hepatol 2003;18:329-32.

111 Kolek $A$, Janout $V$, Tichy $M$, et al. The incidence of inflammatory bowel disease is increasing among children 15 years old and younger in the Czech Republic. J Pediatr Gastroenterol Nutr 2004;38:362-3.

112 Motil KJ, Grand RJ, Davis-Kraft L, et al. Growth failure in children with inflammatory bowel disease: a prospective study. Gastroenterology 1993;105:681-91.

113 Sawczenko A, Sandhu BK. Presenting features of inflammatory bowel disease in Great Britain and Ireland. Arch Dis Child 2003:88:995-1000

114 Gasche C, Scholmerich J, Brynskov J, et al. A simple classification of Crohn's disease: report of the Working Party for the World Congresses of Gastroenterology, Vienna 1998. Inflamm Bowel Dis 2000;6:8-15.

115 Weinstein TA, Levine $M$, Pettei MJ, et al. Age and family history at presentation of pediatric inflammatory bowel disease. J Pediatr Gastroenterol Nutr 2003;37:609-13.

116 Sun L, Roesler J, Rosen-Wolff A, et al. CARD15 genotype and phenotype analysis in 55 pediatric patients with Crohn disease from Saxony, Germany. J Pediatr Gastroenterol Nutr 2003:37:492-7.

117 Escher JC, Amil Dias J, Bochenek K, et al. Inflammatory Bowel Disease in children and adolescents. Recommendations for Diagnosis: The Porto criteria. Medical Position Paper: IBD working group of the European Society for Paediatric Gastroenterology, Hepatology and Nutrition (ESPGHAN) J Pediatr Gastroenterol Nutr 2005:41:1-7.

118 Chong SK, Blackshaw AJ, Boyle S, et al. Histological diagnosis of chronic inflammatory bowel disease in childhood. Gut 1985;26:55-9.

119 Holmquist L, Rudic N, Ahren C, et al. The diagnostic value of colonoscopy compared with rectosigmoidoscopy in children and adolescents with symptoms of chronic inflammatory bowel disease of the colon. Scand I Gastroenterol 1988;23:577-84.

120 Cameron DJ. Upper and lower gastrointestinal endoscopy in children and adolescents with Crohn's disease: a prospective study. J Gastroenterol Hepatol 1991;6:355-8.

121 Williams CB, Nicholls S. Endoscopic features of chronic inflammatory bowel disease in childhood. Baillieres Clin Gastroenterol 1994;8:121-31.

122 Griffiths AMB. H.A. Inflammatory bowel disease. In: Walker WAD PR, Hamilton JR, et al. Pediatric gastrointestinal disease. Pathophysiology, diagnosis, management. Hamilton: BC Decker, 2000:613-51.

123 Escher JC, Ten KF, Lichtenbelt $K$, et al. Value of rectosigmoidoscopy with biopsies for diagnosis of inflammatory bowel disease in children. Inflamm Bowel Dis 2002;8:16-22.

124 Batres LA, Maller ES, Ruchelli E, et al. Terminal ileum intubation in pediatric colonoscopy and diagnostic value of conventional small bowel contrast radiography in pediatric inflammatory bowel disease. J Pediatr Gastroenterol Nutr 2002:35:320-3.

125 Mashako MN, Cezard JP, Navarro J, et al. Crohn's disease lesions in the upper gastrointestinal tract: correlation between clinical, radiological, endoscopic, and histological features in adolescents and children. J Pediatr Gastroenterol Nutr 1989:8:442-6.

126 Abdullah BA, Gupta SK, Croffie JM, et al. The role of esophagogastroduodenoscopy in the initial evaluation of childhood inflammatory bowel disease: a 7-year study. J Pediatr Gastroenterol Nutr 2002:35:636-40.

127 Sharif $F$, McDermott M, Dillon $M$, et al. Focally enhanced gastritis in children with Crohn's disease and ulcerative colitis. Am J Gastroenterol 2002;97:1415-20

128 Castellaneta SP, Afzal NA, Greenberg M, et al. Diagnostic role of upper gastrointestinal endoscopy in pediatric inflammatory bowel disease. J Pediatr Gastroenterol Nutr 2004;39:257-61.

129 Lipson A, Bartram Cl, Williams CB, et al. Barium studies and ileoscopy compared in children with suspected Crohn's disease. Clin Radiol 1990:41:5-8.

130 Halligan S, Nicholls S, Beattie RM, et al. The role of small bowel radiology in the diagnosis and management of Crohn's disease. Acta Paediatr 1995;84:1375-8.

131 Dillon M, Brown S, Casey W, et al. Colonoscopy under general anesthesia in children. Pediatrics 1998;102:381-3.

132 Wengrower D, Gozal D, Gozal Y, et al. Complicated endoscopic pediatric procedures using deep sedation and general anesthesia are safe in the endoscopy suite. Scand J Gastroenterol 2004;39:283-6.

133 Heuschkel RB, Menache CC, Megerian JT, et al. Enteral nutrition and corticosteroids in the treatment of acute Crohn's disease in children. J Pediatr Gastroenterol Nutr 2000;31:8-15

134 Levine A, Weizman Z, Broide E, et al. A comparison of budesonide and prednisone for the treatment of active pediatric Crohn disease. J Pediatr Gastroenterol Nutr 2003;36:248-52.

135 Escher JC. Budesonide versus prednisolone for the treatment of active Crohn's disease in children: a randomized, double-blind, controlled, multicentre trial. Eur J Gastroenterol Hepatol 2004;16:47-54.

136 Markowitz J, Grancher K, Kohn N, et al. A multicenter trial of 6mercaptopurine and prednisone in children with newly diagnosed Crohn's disease. Gastroenterology 2000;119:895-902.

137 Mack DR, Young R, Kaufman SS, et al. Methotrexate in patients with Crohn's disease after 6-mercaptopurine. J Pediatr 1998;132:830-5.
138 Hyams JS, Markowitz J, Wyllie R. Use of infliximab in the treatment of Crohn's disease in children and adolescents. J Pediatr 2000;137:192-6.

139 Kugathasan S, Werlin SL, Martinez A, et al. Prolonged duration of response to infliximab in early but not late pediatric Crohn's disease. Am J Gastroenterol 2000:95:3189-94.

140 Lionetti P, Bronzini F, Salvestrini C, et al. Response to infliximab is related to disease duration in paediatric Crohn's disease. Aliment Pharmacol Ther 2003; 18:425-31.

141 Serrano MS, Schmidt-Sommerfeld E, Kilbaugh TJ, et al. Use of infliximab in pediatric patients with inflammatory bowel disease. Ann Pharmacother 2001;35:823-8

142 Stephens MC, Shepanski MA, Mamula P, et al. Safety and steroid-sparing experience using infliximab for Crohn's disease at a pediatric inflammatory bowel disease center. Am J Gastroenterol 2003:98:104-11.

143 Cezard JP, Nouaili N, Talbotec C, et al. A prospective study of the efficacy and tolerance of a chimeric antibody to tumor necrosis factors (Remicade) in severe pediatric Crohn's disease. J Pediatr Gastroenterol Nutr 2003;36:632-6.

144 Crandall WV, Mackner LM. Infusion reactions to infliximab in children and adolescents: frequency, outcome and a predictive model. Aliment Pharmacol Ther 2003;17:75-84.

145 de Ridder L, Escher JC, Bouquet J, et al. Infliximab therapy in 30 patients with refractory pediatric crohn disease with and without fistulas in the Netherlands. J Pediatr Gastroenterol Nutr 2004;39:46-52.

146 Diamanti A, Papadatou B, Knafelz D, et al. Clinical outcome and safety of periodic infliximab therapy in children and adolescents with Crohn's disease. J Pediatr Gastroenterol Nutr 2004:39:302-3.

147 Lee WS. The use of infliximab in South-East Asian children with severe Crohn's disease. Pediatr Int 2004;46:198-201.

148 Miele E, Markowitz JE, Mamula P, et al. Human antichimeric antibody in children and young adults with inflammatory bowel disease receiving infliximab. J Pediatr Gastroenterol Nutr 2004:38:502-8.

149 Borrelli O, Bascietto C, Viola F, et al. Infliximab heals intestinal inflammatory lesions and restores growth in children with Crohn's disease. Dig Liver Dis 2004:36:342-7.

150 Lipson AB, Savage MO, Davies PS, et al. Acceleration of linear growth following intestinal resection for Crohn disease. Eur J Pediatr 1990;149:687-90.

151 Griffiths AM, Wesson DE, Shandling B, et al. Factors influencing postoperative recurrence of Crohn's disease in childhood. Gut 1991;32:491-5.

152 Besnard M, Jaby O, Mougenot JF, et al. Postoperative outcome of Crohn's disease in 30 children. Gut 1998;43:634-8.

153 Sentongo TA, Stettler N, Christian A, et al. Growth after intestinal resection for Crohn's disease in children, adolescents, and young adults. Inflamm Bowel Dis 2000;6:265-9.

154 Dokucu Al, Sarnacki S, Michel JL, et al. Indications and results of surgery in patients with Crohn's disease with onset under 10 years of age: a series of 18 patients. Eur J Pediatr Surg 2002:12:180-5.

155 Engstrom I, Lindquist BL. Inflammatory bowel disease in children and adolescents: a somatic and psychiatric investigation. Acta Paediatr Scand 1991;80:640-7.

156 van der Zaag-Loonen HJ, Grootenhuis MA, Last BF, et al. Coping strategies and quality of life of adolescents with inflammatory bowel disease. Qual Life Res 2004;13:1011-19.

157 Baird DD, Narendranathan M, Sandler RS. Increased risk of preterm birth for women with inflammatory bowel disease. Gastroenterology 1990:99:987-94.

158 Khosla R, Willoughby CP, Jewell DP. Crohn's disease and pregnancy. Gut 1984;25:52-6

159 Woolfson K, Cohen Z, McLeod RS. Crohn's disease and pregnancy. Dis Colon Rectum 1990;33:869-73.

160 Fonager K, Sorensen HT, Olsen J, et al. Pregnancy outcome for women with Crohn's disease: a follow-up study based on linkage between national registries. Am J Gastroenterol 1998;93:2426-30.

161 Baiocco PJ, Korelitz BI. The influence of inflammatory bowel disease and its treatment on pregnancy and fetal outcome. J Clin Gastroenterol 1984;6:211-16.

162 Mayberry JF, Weterman IT. European survey of fertility and pregnancy in women with Crohn's disease: a case control study by European collaborative group. Gut 1986;27:821-5.

163 Hudson M, Flett G, Sinclair TS, et al. Fertility and pregnancy in inflammatory bowel disease. Int J Gynaecol Obstet 1997;58:229-37.

164 Ording OK, Juul S, Berndtsson I, et al. Ulcerative colitis: female fecundity before diagnosis, during disease, and after surgery compared with a population sample. Gastroenterology 2002;122:15-19.

165 Olsen KO, Joelsson M, Laurberg S, et al. Fertility after ileal pouch-anal anastomosis in women with ulcerative colitis. Br J Surg 1999;86:493-5.

166 Oresland T, Palmblad S, Ellstrom M, et al. Gynaecological and sexual function related to anatomical changes in the female pelvis after restorative proctocolectomy. Int $J$ Colorectal Dis 1994:9:77-81.

167 Ravid A, Richard CS, Spencer LM, et al. Pregnancy, delivery, and pouch function after ileal pouch-anal anastomosis for ulcerative colitis. Dis Colon Rectum 2002;45:1283-8.

168 Tiainen J, Matikainen M, Hiltunen KM. lleal J-pouch-anal anastomosis, sexual dysfunction, and fertility. Scand J Gastroenterol 1999:34:185-8.

169 Juhasz ES, Fozard B, Dozois RR, et al. lleal pouch-anal anastomosis function following childbirth. An extended evaluation. Dis Colon Rectum 1995;38:159-65.

170 Damgaard B, Wettergren A, Kirkegaard P. Social and sexual function following ileal pouch-anal anastomosis. Dis Colon Rectum 1995;38:286-9. 
171 Johnson E, Carlsen E, Nazir M et al. Morbidity and functional outcome after restorative proctocolectomy for ulcerative colitis. Eur J Surg 2001;167:40-5.

172 Levi AJ, Fisher AM, Hughes L, et al. Male infertility due to sulphasalazine. Lancet 1979:2:276-8.

173 Birnie GG, McLeod TI, Watkinson G. Incidence of sulphasalazine-induced male infertility. Gut 1981;22:452-5.

174 O'Morain C, Smethurst P, Dore CJ, et al. Reversible male infertility due to sulphasalazine: studies in man and rat. Gut 1984;25:1078-84.

175 Toth A. Reversible toxic effect of salicylazosulfapyridine on semen quality. Fertil Steril 1979;31:538-40.

176 Dejaco C, Mittermaier C, Reinisch W, et al. Azathioprine treatment and male fertility in inflammatory bowel disease. Gastroenterology 2001; 121:1048-53.

177 Narendranathan M, Sandler RS, Suchindran CM, et al. Male infertility in inflammatory bowel disease. J Clin Gastroenterol 1989;11:403-6.

178 Hanan IM, Kirsner JB. Inflammatory bowel disease in the pregnant woman. Clin Perinatol 1985; 12:669-82.

179 Larzilliere I, Beau P. [Chronic inflammatory bowel disease and pregnancy. Case control study]. Gastroenterol Clin Biol 1998;22:1056-60.

180 Miller JP. Inflammatory bowel disease in pregnancy: a review. J R Soc Med 1986;79:221-5

181 Korelitz BI. Inflammatory bowel disease and pregnancy. Gastroenterol Clin North Am 1998;27:213-24.

182 Fedorkow DM, Persaud D, Nimrod CA. Inflammatory bowel disease: a controlled study of late pregnancy outcome. Am J Obstet Gynecol 1989; 160:998-1001.

183 Mogadam M, Dobbins WO III, Korelitz BI, et al. Pregnancy in inflammatory bowel disease: effect of sulfasalazine and corticosteroids on fetal outcome. Gastroenterology 1981;80:72-6.

184 Alstead EM. Inflammatory bowel disease in pregnancy. Postgrad Med J 2002;78:23-6.

185 Castiglione F, Pignata S, Morace F, et al. Effect of pregnancy on the clinical course of a cohort of women with inflammatory bowel disease. Ital J Gastroenterol 1996;28:199-204.

186 Nwokolo CU, Tan WC, Andrews HA, et al. Surgical resections in parous patients with distal ileal and colonic Crohn's disease. Gut 1994;35:220-3.

187 Buyon JP. The effects of pregnancy on autoimmune diseases. J Leukoc Biol 1998:63:281-7

188 Inyckyji A, Blanchard JF, Rawsthorne P, et al. Perianal Crohn's disease and pregnancy: role of the mode of delivery. Am J Gastroenterol 1999;94:3274-8.

189 Nelson H, Dozois RR, Kelly KA, et al. The effect of pregnancy and delivery on the ileal pouch-anal anastomosis functions. Dis Colon Rectum 1989;32:384-8

190 Ramalingam T, Box B, Mortensen NM. Pregnancy delivery and pouch function after ileal pouch-anal anastomosis for ulcerative colitis. Dis Colon Rectum 2003:46:1292.

191 Scott HJ, McLeod RS, Blair J, et al. Ileal pouch-anal anastomosis: pregnancy, delivery and pouch function. Int J Colorectal Dis 1996;11:84-7.

192 Nicholl MC, Thompson JM, Cocks PS. Stomas and pregnancy. Aust N Z J Obstet Gynaecol 1993;33:322-4.

193 Brandt L, Estabrook SG, Reinus JF. Results of a survey to evaluate whether vaginal delivery and episiotomy lead to perineal involvement in women with Crohn's disease. Am J Gastroenterol 1995;90:1918-22.

194 Subhani JM, Hamiliton MI. Review article: The management of inflammatory bowel disease during pregnancy. Aliment Pharmacol Ther 1998; 12:1039-53.

195 Nielsen OH, Andreasson B, Bondesen S, et al. Pregnancy in Crohn's disease. Scand J Gastroenterol 1984;19:724-32.

196 Hill J, Clark A, Scott NA. Surgical treatment of acute manifestations of Crohn's disease during pregnancy. J R Soc Med 1997;90:64-6.

197 Kane S. Inflammatory bowel disease in pregnancy. Gastroenterol Clin North Am 2003:32:323-40.

198 Jarnerot G, Into-Malmberg MB. Sulphasalazine treatment during breast feeding. Scand J Gastroenterol 1979;14:869-71.

199 Khan AK, Truelove SC. Placental and mammary transfer of sulphasalazine. BMJ 1979;ii: 1553.

200 Esbjorner E, Jarnerot G, Wranne L. Sulphasalazine and sulphapyridine serum levels in children to mothers treated with sulphasalazine during pregnancy and lactation. Acta Paediatr Scand 1987;76:137-42.

201 Diav-Citrin O, Park YH, Veerasuntharam G, et al. The safety of mesalamine in human pregnancy: a prospective controlled cohort study.

Gastroenterology 1998;114:23-8.

202 Habal FM, Hui G, Greenberg GR. Oral 5-aminosalicylic acid for inflammatory bowel disease in pregnancy: safety and clinical course. Gastroenterology 1993;105:1057-60.

203 Marteau P, Devaux CB. Mesalazine during pregnancy. Lancet 1994;344:1708-9

204 Trallori G, d'Albasio G, Bardazzi G, et al. 5-Aminosalicylic acid in pregnancy: clinical report. Ital J Gastroenterol 1994;26:75-8.

205 Norgard B, Fonager K, Pedersen L, et al. Birth outcome in women exposed to 5-aminosalicylic acid during pregnancy: a Danish cohort study. Gut 2003;52:243-7

206 Present DH. How to do without steroids in inflammatory bowel disease. Inflamm Bowel Dis 2000;6:48-57.

207 Burtin P, Taddio A, Ariburnu O, et al. Safety of metronidazole in pregnancy: a meta-analysis. Am J Obstet Gynecol 1995;172:525-9.

208 Loebstein R, Addis A, Ho E, et al. Pregnancy outcome following gestational exposure to fluoroquinolones: a multicenter prospective controlled study. Antimicrob Agents Chemother 1998;42:1336-9.
209 Schaefer C, moura-Elefant E, Vial T, et al. Pregnancy outcome after prenatal quinolone exposure. Evaluation of a case registry of the European Network of Teratology Information Services (ENTIS). Eur J Obstet Gynecol Reprod Bio 1996:69:83-9.

210 Brumfitt W, Pursell R. Trimethoprim-sulfamethoxazole in the treatment of bacteriuria in women. J Infect Dis 1973;128(suppl 65).

211 Decosta EJ, Belman MA. Cortisone and pregnancy; an experimental and clinical study of the effects of cortisone on gestation. Am J Obstet Gynecol 1952;64:746-67.

212 Koren G, Pastuszak A, Ito S. Drugs in pregnancy. N Engl J Med 1998;338:1128-37

213 Ferrero S, Ragni N. Inflammatory bowel disease: management issues during pregnancy. Arch Gynecol Obstet 2004;270:79-85.

214 Norjavaara E, de Verdier MG. Normal pregnancy outcomes in a population-based study including 2,968 pregnant women exposed to budesonide. J Allergy Clin Immunol 2003;1 11:736-42.

215 Kallen B, Rydhstroem H, Aberg A. Congenital malformations after the use of inhaled budesonide in early pregnancy. Obstet Gynecol 1999:93:392-5.

216 Kihlstrom I, Lundberg C. Teratogenicity study of the new glucocorticosteroid budesonide in rabbits. Arzneimittelforschung 1987;37:43-6.

217 Bermas BL, Hill JA. Effects of immunosuppressive drugs during pregnancy. Arthritis Rheum 1995:38:1722-32.

218 Roubenoff R, Hoyt J, Petri $M$, et al. Effects of antiinflammatory and immunosuppressive drugs on pregnancy and fertility. Semin Arthritis Rheum 1988;18:88-110.

219 Willis FR, Findlay CA, Gorrie MJ, et al. Children of renal transplant recipient mothers. J Paediatr Child Health 2000;36:230-5.

220 Blatt J, Mulvihill JJ, Ziegler JL, et al. Pregnancy outcome following cancer chemotherapy. Am J Med 1980;69:828-32.

221 Nicholson HO. Cytotoxic drugs in pregnancy. Review of reported cases. J Obstet Gynaecol Br Commonw 1968:75:307-12.

222 Platzek T, Bochert G. Dose-response relationship of teratogenicity and prenatal-toxic risk estimation of 6-mercaptopurine riboside in mice. Teratog Carcinog Mutagen 1996;16:169-81.

223 Mosesso P, Palitti F. The genetic toxicology of 6-mercaptopurine. Mutat Res 1993;296:279-94.

224 Alstead EM, Ritchie JK, Lennard-Jones JE, et al. Safety of azathioprine in pregnancy in inflammatory bowel disease. Gastroenterology 1990;99:443-6.

225 Francella A, Dyan A, Bodian C, et al. The safety of 6-mercaptopurine for childbearing patients with inflammatory bowel disease: a retrospective cohort study. Gastroenterology 2003;124:9-17.

226 Dejaco C, Angelberger S, Waldhoer T, et al. Pregnancy and birth outcome under thiopurine therapy for inflammatory bowel disease. Gastroenterology 2005; 128(suppl 2):A12.

227 Rajapakse RO, Korelitz BI, Zlatanic J, et al. Outcome of pregnancies when fathers are treated with 6-mercaptopurine for inflammatory bowel disease. Am J Gastroenterol 2000;95:684-8.

228 Bar OB, Hackman R, Einarson T, et al. Pregnancy outcome after cyclosporine therapy during pregnancy: a meta-analysis. Transplantation 2001;71:1051-5.

229 Armenti VT, Ahlswede KM, Ahlswede BA, et al. National transplantation Pregnancy Registry-outcomes of 154 pregnancies in cyclosporine-treated female kidney transplant recipients. Transplantation 1994;57:502-6.

230 Radomski JS, Ahlswede BA, Jarrell BE, et al. Outcomes of 500 pregnancies in 335 female kidney, liver, and heart transplant recipients. Transplant Proc 1995;27:1089-90.

231 Bertschinger P, Himmelmann A, Risti B, et al. Cyclosporine treatment of severe ulcerative colitis duringl pregnancy. Am J Gastroenterol 1995;90:330

232 Kainz A, Harabacz I, Cowlrick IS, et al. Review of the course and outcome of 100 pregnancies in 84 women treated with tacrolimus. Transplantation 2000;70:1718-21.

233 Kozlowski RD, Steinbrunner JV, MacKenzie AH, et al. Outcome of firsttrimester exposure to low-dose methotrexate in eight patients with rheumatic disease. Am J Med 1990;88:589-92.

234 Kane S. Managing pregnancy in IBD. Inflammatory Bowel Disease Monitor 2002;4:2-11.

235 Vasiliauskas $E$, Dubinsky $M$, Barry $M$, et al. High serum levels of infliximab in the newborn of a mother receiving infliximab during pregnancy. Gastroenterology 2005; 128(suppl 2):A26.

236 Calabrese L, Fleischer AB. Thalidomide: current and potential clinical applications. Am J Med 2000;108:487-95.

237 Smithells RW, Newman CG. Recognition of thalidomide defects. J Med Genet 1992;29:716-23.

238 Pinder RM, Brogden RN, Sawyer PR, et al. Metoclopramide: a review of its pharmacological properties and clinical use. Drugs 1976;12:81-131.

239 Sahakian V, Rouse D, Sipes S, et al. Vitamin B6 is effective therapy for nausea and vomiting of pregnancy: a randomized, double-blind placebocontrolled study. Obstet Gynecol 1991;78:33-6.

240 Siu SS, Yip SK, Cheung CW, et al. Treatment of intractable hyperemesis gravidarum by ondansetron. Eur J Obstet Gynecol Reprod Biol 2002; 105:73-4.

241 Larson JD, Patatanian E, Miner PB, et al. Double-blind, placebo-controlled study of ranitidine for gastroesophageal reflux symptoms during pregnancy. Obstet Gynecol 1997:90:83-7.

242 Nikfar S, Abdollahi M, Moretti ME, et al. Use of proton pump inhibitors during pregnancy and rates of major malformations: a meta-analysis. Dig Dis Sci 2002;47:1526-9.

243 Stuart MJ, Gross SJ, Elrad H, et al. Effects of acetylsalicylic-acid ingestion on maternal and neonatal hemostasis. N Engl J Med 1982;307:909-12. 
244 Kane S, Hanaver S. Fertility and pregnancy. In: Balfour Sartor R, Sandborn WJ, eds. Kirsner's inflammatory bowel disease. Philadelphia: Saunders, 2004:333-9.

245 Baron TH, Ramirez B, Richter JE. Gastrointestinal motility disorders during pregnancy. Ann Intern Med 1993;1 18:366-75.

246 Marteau P, Tennenbaum R, Elefant E, et al. Foetal outcome in women with inflammatory bowel disease treated during pregnancy with oral mesalazine microgranules. Aliment Pharmacol Ther 1998;12:1101-8.

247 Beitins IZ, Bayard F, Ances IG, et al. The transplacental passage of prednisone and prednisolone in pregnancy near term. J Pediatr 1972;81:936-45.

248 Ost L, Wettrell G, Bjorkhem I, et al. Prednisolone excretion in human milk. J Pediatr 1985;106:1008-11.

249 Christensen LA, Dahlerup JF, Schmiegelow K. Excretion of azathioprine metabolites in maternal milk. Gut 2005;54(suppl VII):A45.

250 Drossman DA. Presidential Address: Gastrointestinal illness and biopsychosocial model. Psychosom Med 1998;60:258-67.

251 Rubin GP, Hungin AP, Chinn DJ, et al. Quality of life in patients with established inflammatory bowel disease: a UK general practice survey. Aliment Pharmacol Ther 2004; 19:529-35.

252 Guthrie E, Jackson J, Shaffer J, et al. Psychological disorder and severity of inflammatory bowel disease predict health-related quality of life in ulcerative colitis and Crohn's disease. Am J Gastroenterol 2002:97:1994-9.

253 Nordin K, Pahlman L, Larsson K, et al. Health-related quality of life and psychological distress in a population-based sample of Swedish patients with inflammatory bowel disease. Scand J Gastroenterol 2002;37:450-7.

254 Kurina LM, Goldacre MJ, Yeates D, et al. Depression and anxiety in people with inflammatory bowel disease. J Epidemiol Community Health 2001;55:716-20.

255 Drossman DA, Leserman J, Mitchell CM, et al. Health status and health care use in persons with inflammatory bowel disease. A national sample. Dig Dis Sci 1991;36:1746-55.

256 Helzer JE, Chammas S, Norland CC, et al. A study of the association between Crohn's disease and psychiatric illness. Gastroenterology 1984:86:324-30.

257 Casellas F, Lopez-Vivancos J, Badia X, et al. Influence of inflammatory bowel disease on different dimensions of quality of life. Eur J Gastroenterol Hepatol 2001; 13:567-72.

258 Cohen RD. The quality of life in patients with Crohn's disease. Aliment Pharmacol Ther 2002;16:1603-9.

259 Guassora AD, Kruuse C, Thomsen OO, et al. Quality of life study in a regional group of patients with Crohn's disease. A structured interview study. Scand J Gastroenterol 2000;35:1068-74.

260 Addolorato G, Capristo E, Stefanini GF, et al. Inflammatory bowel disease: a study of the association between anxiety and depression, physical morbidity, and nutritional status. Scand J Gastroenterol 1997;32:1013-21.

261 Porcelli P, Leoci C, Guerra V. A prospective study of the relationship between disease activity and psychologic distress levels in patients with inflammatory bowel disease. Scand J Gastroenterol 1996:31:792-6.

262 Li J, Norgard B, Precht DH, et al. Psychological stress and inflammatory bowel disease: a follow-up study in parents who lost a child in Denmark. Am J Gastroenterol 2004;99:1129-33.

263 Engström I, Lindquist BL. Inflammatory bowel disease in children and adolescents: a somatic and psychiatric investigation. Acta Paediatr Scand 1991;89:640-7

264 Mittermaier C, Dejaco C, Waldhoer T, et al. Impact of depressive mood on relapse in patients with IBD: a prospective 18-month follow-up study. Psychosom Med 2004;66:79-84.

265 Mardini HE, Kip KE, Wilson JW. Crohn's disease: a two-year prospective study of the association between psychological distress and disease activity. Dig Dis Sci 2004;49:492-7.

266 Andrews H, Barczak P, Allan RN. Psychiatric illness in patients with inflammatory bowel disease. Gut 1987;28:1600-4.

267 Wietersheim J, Kohler T, Feiereis H. Relapse-precipitating life events and feelings in patients with inflammatory bowel disease. Psychother Psychosom 1992;58:103-12.

268 North CS, Alpers DH, Helzer JE, et al. Do life events or depression exacerbate inflammatory bowel disease? A prospective study. Ann Intern Medicine 1991;114:381-6.

269 Duffy LC, Zielezny MA, Marshall JR, et al. Relevance of major stress events as an indicator of disease activity prevalence in inflammatory bowel disease. Behav Med 1991;17:101-10.

270 Gomez-Gil E, Vidal A, Panes J, et al. Relationship between patient's subjective stress perception and the course of inflammatory bowel disease. Gastroenterol Hepatol 2003;26:411-16.

271 Robertson DA, Ray J, Diamond I, et al. Personality profile and affective state of patients with inflammatory bowel disease. Gut 1989;30:623-6.

272 Nigro G, Angelini G, Grosso SB, et al. Psychiatric predictors of noncompliance in inflammatory bowel disease. J Clin Gastroenterol 2001;32:66-8.

273 Sewitch MJ, Abrahamowicz M, Bitton A, et al. Psychosocial correlates of patient-physician discordance in inflammatory bowel disease. Am J Gastroenterol 2002;97:2174-83.

274 Wietersheim J, Jantschek G, Sommer W, et al. Education of patients with inflammatory bowel diseases. Wien Med Wochenschr 1999;149:352-4.

275 Moser G, Tillinger W, Sachs G, et al. Disease-related worries and concerns: a study on out-patients with inflammatory bowel disease. Eur J Gastroenterol Hepatol 1995;9:853-8.

276 Kennedy A, Nelson E, Reeves D, et al. A randomised controlled trial to assess the impact of a package comprising a patient-orientated, evidencebased self-help guidebook and patient-centred consultations on disease management and satisfaction in inflammatory bowel disease. Health Technol Assess 2003;7:iii 1-113

277 Kennedy AP, Nelson E, Reeves D, et al. A randomised controlled trial to assess the effectiveness and cost of a patient orientated self management approach to chronic inflammatory bowel disease. Gut 2004;53:1639-45.

278 Borgaonkar MR, Townson G, Donnelly M, et al. Providing disease-related information worsens health-related quality of life in inflammatory bowel disease. Inflamm Bowel Dis 2002;8:264-9.

279 Lange A, Haslbeck E, Andus T, et al. Patient education in inflammatory bowel disease. Z Gastroenterol 1996;34:411-15.

280 Larsson K, Sundberg Hielm M, et al. A group-based patient education programme for high-anxiety patients with Crohn disease or ulcerative colitis. Scand J Gastroenterol 2003:38:763-9.

281 Sewitch MJ, Abrahamowicz M, Barkun A, et al. Patient nonadherence to medication in inflammatory bowel disease. Am J Gastroenterol 2003;98:1535-44.

282 Guyatt GH, Mitchell A, Irvine EJ, et al. A new measure of health status for clinical trials in inflammatory bowel disease. Gastroenterology 1989;96:804-10.

283 Irvine EJ, Zhou Q, Thompson AK, and the CCRPT Investigators. The short inflammatory bowel disease questionnaire: A quality of life instrument for community physicians managing inflammatory bowel disease. Am J Gastroenterol 1996;91:1571-8.

284 Drossman DA, Leserman J, Li Z, et al. The rating form of IBD patient concerns: A new measure of health status. Psychosom Med 1991;53:701-12.

285 Miehsler W, Weichselberger M, Offerlbaver-Ernst A, et al. Assessing the demand for psychological care in chronic diseases: development and validation of a questionnaire based on the example of inflammatory bowel disease. Inflamm Bowel Dis 2004;10:637-45.

286 Moser G. Psychosomatics [Diagnostics and treatment of Crohn's diseaseresults of an evidence-based consensus conference of the German Society for Digestive and Metabolic Diseases]. Z Gastroenterol 2003;41:50-1.

287 Moser G, Jantschek G. Psychosomatic [Diagnosis and therapy of ulcerative colitis: Results of an evidence-based consensus conference by the German Society of Digestive and Metabolic Diseases and the Competence Network on Inflammatory Bowel Disease]. Z Gastroenterol 2004;42:1038-40.

288 Sewitch MJ, Abrahamowicz M, Bitton A, et al. Psychological distress, social support, and disease activity in patients with inflammatory bowel disease. Am J Gastroenterol 2001;96:1470-9.

289 Mussell M, Bocker U, Nagel N, et al. Reducing psychological distress in patients with inflammatory bowel disease by cognitive-behavioural treatment: exploratory study of effectiveness. Scand J Gastroenterol 2003;38:755-62

290 Schwarz SP, Blanchard EB. Evaluation of psychological treatment for inflammatory bowel disease. Behav Res Ther 1991;29:167-77.

291 Milne B, Joachim G, Niedhardt J. A stress management program for inflammatory bowel disease patients. J Advan Nurs 1986;1 1:561-7.

292 Jantschek G, Zeitz M, Pritsch M, et al. Effect of psychotherapy on the course of Crohn's disease. Results of the German prospective multicenter psychotherapy treatment study on Crohn's disease. German Study Group on Psychosocial Intervention in Crohn's Disease. Scand J Gastroenterol 1998;33:1289-96.

293 Keller W, Pritsch M, Von Wietersheim J, et al. The German Study Group on Psychosocial Intervention in Crohn's Disease. Effect of psychotherapy and relaxation on the psychosocial and somatic course of Crohn's disease: main results of the German prospective multicenter psychotherapy treatment study on Crohn's disease. J Psychosom Res 2004;56:687-96.

294 Garcia-Vega E, Fernandez-Rodriguez C. A stress management programme for Crohn's disease. Behav Res Ther 2004;42:367-83.

295 Maunder RG, Esplen MJ. Supportive-expressive group psychotherapy for persons with inflammatory bowel disease. Can J Psychiatry 2001;46:622-6.

296 Su CG, Judge TA, Lichtenstein GR. Extraintestinal manifestations of inflammatory bowel disease. Gastroenterol Clin North Am 2002;31:307-27.

297 Farmer RG, Hawk WA, Turnbull RB Jr. Clinical patterns in Crohn's disease: a statistical study of 615 cases. Gastroenterology 1975;68:627-35.

298 Rankin GB, Watts HD, Melnyk CS. National cooperative Crohn's disease study: extraintestinal manifestations and perianal complications. Gastroenterology 1979;77:914-20.

299 Orchard TR, Wordsworth BP, Jewell DP. Peripheral arthropathies in inflammatory bowel disease: their articular distribution and natural history. Gut 1998;42:387-91.

300 Fornaciari G, Salvarani C, Beltrami M, et al. Musculoskeletal manifestations in inflammatory bowel disease. Can J Gastroenterol 2001;15:399-403.

301 Puhakka KB, Jurik AG, Schiottz-Chritensen B, et al. MRI abnormalities of sacroiliac joints in early spondylarthropathy: a 1-year follow-up study. Scand J Rheumatol 2004;33:332-8

302 Braun J, Baraliakos X, Golder W, et al. Analysing chronic spinal changes in ankylosing spondylitis: a systematic comparison of conventional $x$ rays with magnetic resonance imaging using established and new scoring systems. Ann Rheum Dis 2004;63:1046-55.

303 Bjarnason I, Helgason KO, Geirsson AJ, et al. Subclinical intestinal inflammation and sacroiliac changes in relatives of patients with ankylosing spondylitis. Gastroenterology 2003;125:1598-605.

304 Steer S, Jones H, Hibbert J, et al. Low back pain, sacroiliitis, and the relationship with HLA-B27 in Crohn's disease. J Rheumatol 2003;30:518-22

305 Ferraz MB, Tugwell P, Goldsmith CH, et al. Meta-analysis of sulfasalazine in ankylosing spondylitis. J Rheumatol 1990;17:1482-6. 
306 Dougados M, Dijkmans B, Khan M, et al. Conventional treatment for ankylosing spondylitis. Ann Rheum Dis 2002;61:40-50.

307 Cipolla G, Crema F, Sacco S, et al. Nonsteroidal anti-inflammatory drugs and inflammatory bowel disease: current perspectives. Pharmacol Res 2002;46:1-6.

308 Evans JM, McMahon AD, Murray FE, et al. Non-steroidal anti-inflammatory drugs are associated with emergency admission to hospital for colitis due to inflammatory bowel disease. Gut 1997;40:619-22

309 McCartney SA, Mitchell JA, Fairclough PD, et al. Selective COX-2 inhibitors and human inflammatory bowel disease. Aliment Pharmacol Ther 1999;13:1115-17.

310 Von Bodegraven A, Pena A. Treatment of extraintestinal manifestation in inflammatory bowel disease. Curr Treat Options Gastroenterol 2003:6:201-12.

311 Braun J, Brandt J, Listing J, et al. Treatment of active ankylosing spondylitis with infliximab: a randomised controlled multicentre trial. Lancet 2002;359: 1187-93.

312 Van den Bosch F, Kruithof E, Baeten D, et al. Randomised double blind comparison of chimeric monoclonal antibody to tumour necrosis factor alpha (infliximab) versus placebo in active spondyloarthropathy. Arthr Rheum 2002;46:755-65.

313 Scott EM, Gaywood I, Scott BB. British Society of Gastroenterology: Guidelines for osteoporosis in coeliac disease and inflammatory bowel disease. Gut 2000;46(suppl 1):i1-8.

314 Loftus EV Jr, Achenbach SJ, Sandborn WJ, et al. Risk of fracture in ulcerative colitis: a population-based study from Olmsted County, Minnesota. Clin Gastroenterol Hepatol 2003;1:465-73.

315 Nelson HD, Humphrey LL, Nygren P, et al. Postmenopausal hormone replacement therapy: scientific review. JAMA 2002;288:872-81.

316 Stevenson M, Lloyd Jones M, De Nigris E, et al. A systematic review and economic evaluation of alendronate, etidronate, risedronate, raloxifene and teriparatide for the prevention and treatment of postmenopausal osteoporosis. Health Technol Assess 2005;9:1-160.

317 Diamond TH. Pharmacotherapy of osteoporosis in men. Expert Opin Pharmacother 2005;6:45-58.

318 Requena L, Requena C. Erythema nodosum. Dermatol Online J 2002;8:4-8.

319 Chow R K, Ho VC. Treatment of pyoderma gangrenosum. J Am Acad Dermatol 1996;34:1047-60.

320 Matis WL, Ellis CN, Griffiths CE, et al. Treatment of pyoderma gangrenosum with cyclosporine. Arch Dermatol 1992;128:1060-4

321 Jolles S, Niclasse S, Benson E. Combination oral and topical tacrolimus in therapy-resistant pyoderma gangrenosum. Br J Dermatol 1999; 140:564-65.

322 Liung T, Staun M, Grove $O$, et al. Pyoderma gangrenosum associated with Crohn's disease: effect of TNF alpha blockade with infliximab. Scand J Gastroenterol 2002:37:1 108-10.

323 Brooklyn T, Dunnill GS, Shetty A, et al. Infliximab for the treatment of pyoderma gangrenosusm: a randomised, double-blind placebo-controlled trial. Gut, 2005; Sep 27; epub ahead of print.

324 Mintz R, Feller ER, Bahr RL, et al. Ocular manifestations of inflammatory bowel disease. Inflamm Bowel Dis 2004;10:135-9.
325 Vitellas KM, Enns RA, Keogan MT, et al. Comparison of MR cholangiopancreatographic techniques with contrast-enhanced cholangiography in the evaluation of sclerosing cholangitis. Am J Roentgenol 2002; 178:327-34.

326 Talwalkar JA, Angulo P, Johnson CD, et al. Cost-minimization analysis of $M R C$ versus ERCP for the diagnosis of primary sclerosing cholangitis. Hepatology 2004;40:39-45.

327 MacFaul GR, Chapman RW. Sclerosing cholangitis. Curr Opin Gastroenterol 2004;20:275-80.

328 Lindor KD, and The Mayo Primary Sclerosing Cholangitis-Ursodeoxycholic acid Study Group. Ursodiol for primary sclerosing cholangitis. N Engl J Med 1997:336:691-5.

329 Mitchell SA, Bansi DS, Hunt N, et al. A preliminary trial of high-dose ursodeoxycholic acid in primary sclerosing cholangitis. Gastroenterology 2001;121:900-7.

330 Sjoqvist U, Tribukait B, Ost A, et al. Ursodeoxycholic acid treatment in IBDpatients with colorectal dysplasia and/or DNA-aneuploidy: a prospective, double-blind, randomized controlled pilot study. Anticancer Res 2004; 24:3121-7.

331 Van Thiel DH, Carroll P, Abu-Elmagd K, et al. Tacrolimus, a treatment for primary sclerosing cholangitis: results of an open label preliminary trial. Am J Gastroenterol 1995;90:455-9.

332 Hilsden RJ, Verhoef MJ, Best A, et al. Complementary and alternative medicine use by Canadian patients with inflammatory bowel disease: results from a national survey. Am J Gastroenterol 2003;98:1563-8.

333 Langhorst J, Anthonisen IB, Steder-Neukamm U, et al. Amount of systemic steroid medication is a strong predictor for the use of complementary and alternative medicine in patients with inflammatory bowel disease: results from a German national survey. Inflamm Bowel Dis 2005; 11:287-95.

334 Burgmann T, Rawsthorne P, Bernstein CN. Predictors of alternative and complementary medicine use in inflammatory bowel disease: do measures of conventional health care utilization relate to use? Am J Gastroenterol 2004;99:889-93.

335 Dick A, Keady S, Mohamed F, et al. Use of unlicensed and off-label medications in paediatric gastroenterology with a review of the commonly used formularies in the UK. Aliment Pharmacol Ther 2003;17:571-5.

336 Gerhardt $H$, Seifert $F$, Buvari $P$, et al. Therapy of active Crohn disease with Boswellia serrata extract H 15. Z Gastroenterol 2001;39:1 1-17.

337 Gupta I, Parihar A, Malhotra P, et al. Effects of Boswellia serrata gum resin in patients with ulcerative colitis. Eur J Med Res 1997:2:37-43.

338 Langmead L, Feakins RM, Goldthorpe S, et al. Randomized, double-blind, placebo-controlled trial of oral aloe vera gel for active ulcerative colitis. Aliment Pharmacol Ther 2004; 19:739-47.

339 Joos S, Brinkhaus B, Maluche C, et al. Acupuncture and moxibustion in the treatment of active Crohn's disease: a randomized controlled study. Digestion 2004;69:131-9.

340 Belluzzi A, Brignola C, Campieri M, et al. Effect of an enteric-coated fish-oil preparation on relapses in Crohn's disease. N Engl J Med 1996;334:1557-60 